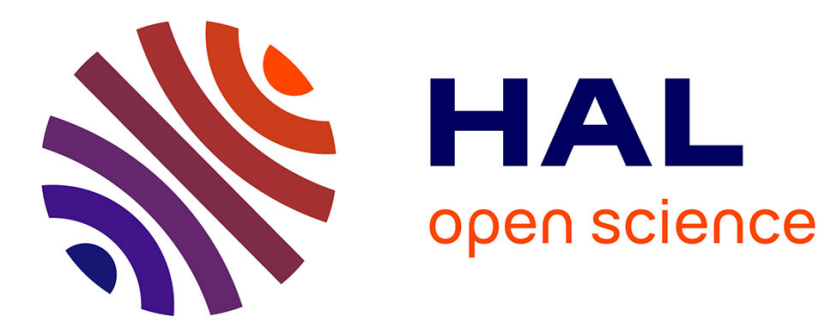

\title{
Deep-UV Rayleigh Scattering of N2, CH4 and SF6
}

\author{
Dmitry Ityaksov, Harold Linnartz, Wim Ubachs
}

\section{To cite this version:}

Dmitry Ityaksov, Harold Linnartz, Wim Ubachs. Deep-UV Rayleigh Scattering of N2, CH4 and SF6.

Molecular Physics, 2008, 106 (21-23), pp.2471-2479. 10.1080/00268970802570334 . hal-00513234

\section{HAL Id: hal-00513234 \\ https://hal.science/hal-00513234}

Submitted on 1 Sep 2010

HAL is a multi-disciplinary open access archive for the deposit and dissemination of scientific research documents, whether they are published or not. The documents may come from teaching and research institutions in France or abroad, or from public or private research centers.
L'archive ouverte pluridisciplinaire HAL, est destinée au dépôt et à la diffusion de documents scientifiques de niveau recherche, publiés ou non, émanant des établissements d'enseignement et de recherche français ou étrangers, des laboratoires publics ou privés. 


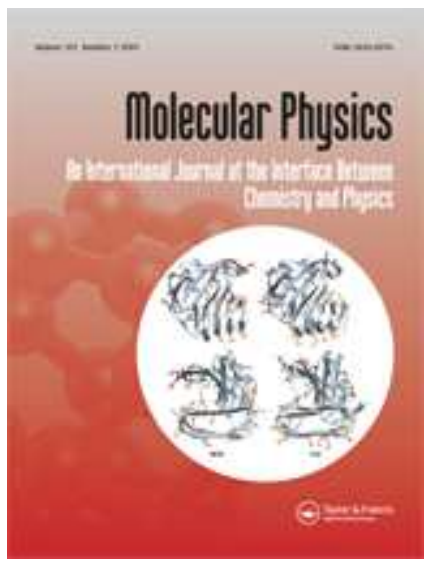

\section{Deep-UV Rayleigh Scattering of N2, CH4 and SF6}

\begin{tabular}{|c|c|}
\hline Journal: & Molecular Physics \\
\hline Manuscript ID: & TMPH-2008-0252.R1 \\
\hline Manuscript Type: & Full Paper \\
\hline $\begin{array}{l}\text { Date Submitted by the } \\
\text { Author: }\end{array}$ & $16-O c t-2008$ \\
\hline Complete List of Authors: & $\begin{array}{l}\text { Ityaksov, Dmitry; Laser Centre Vrije Universiteit Amsterdam, } \\
\text { Physics and Astronomy } \\
\text { Linnartz, Harold; Leiden Observatory/University of Leiden, } \\
\text { Raymond and Sackler Laboratory for Astrophysics } \\
\text { Ubachs, Wim; Laser Centre Vrije Universiteit Amsterdam, Physics } \\
\text { and Astronomy }\end{array}$ \\
\hline Keywords: & $\begin{array}{l}\text { Rayleigh scattering, optical extinction, cavity ring-down } \\
\text { spectroscopy, atmospheric molecules }\end{array}$ \\
\hline
\end{tabular}

\section{scholaroNE \\ Manuscript Central}




\title{
Deep-UV Rayleigh Scattering of $\mathrm{N}_{2}, \mathrm{CH}_{4}$ and $\mathrm{SF}_{6}$
}

\author{
D. Ityaksov ${ }^{1}$, H. Linnartz ${ }^{1,2}$ and W. Ubachs ${ }^{1}$ \\ ${ }^{1}$ Laser Center Vrije Universiteit, De Boelelaan 1081, NL 1081 HV Amsterdam, the Netherlands \\ ${ }^{2}$ Raymond and Beverly Sackler Laboratory for Astrophysics, Leiden Observatory, \\ University of Leiden, P.O. Box 9513, NL 2300 RA Leiden, the Netherlands
}

\begin{abstract}
$\underline{\text { Abstract }}$
Rayleigh scattering room temperature cross-section values of $\mathrm{N}_{2}, \mathrm{CH}_{4}$ and $\mathrm{SF}_{6}$ have been obtained between 198 and $270 \mathrm{~nm}$ by combining cavity ring-down spectroscopy (CRDS) and pressure ramp measurements. The experimental data have been fitted to a functional representation, describing the $\sim 1 / \lambda^{4}$ like behavior of the Rayleigh scattering cross section over a wide wavelength range. The resulting values are compared to numerical predictions, based on refractive indices and molecular anisotropy data as available from literature. From this, values of molecular volume polarizability $\alpha_{\mathrm{vol}}$ and depolarization ratios are derived. It is found that the optical extinction for all three gases is governed by Rayleigh scattering for wavelengths down to $200 \mathrm{~nm}$. No absorption onsets in the specified deep-UV region have been observed.
\end{abstract}

Keywords: Rayleigh scattering, optical extinction, cavity ring-down spectroscopy, atmospheric molecules 


\section{$\underline{\text { Introduction }}$}

Detailed information of Rayleigh scattering processes is a prerequisite to quantitatively interpret e.g. atmospheric and laser diagnostic results $[1,2,3]$. This is particularly true for deep-UV wavelengths as light scattering phenomena intensify because of the $1 / \lambda^{4}$ scaling of the Rayleigh scattering. Furthermore, optical extinction studies are important to verify whether or not constituents exhibit absorption in addition to Rayleigh scattering. The absorption onset for $\mathrm{CO}_{2}$ in the atmospherically relevant window around $200 \mathrm{~nm}$, for example, has been known for many years [4] and was studied in detail recently $[5,6]$. In laser diagnostics Rayleigh scattering cross sections are needed to determine gas density and temperature distribution, e.g. in combustion or flow media [7]. In this paper the focus is on three molecular and atmospherically relevant species: $\mathrm{N}_{2}, \mathrm{CH}_{4}$ and $\mathrm{SF}_{6}$.

Molecular nitrogen is the most abundant molecule in the Earth's atmosphere and consequently information on the absorption and scattering of UV solar radiation by $\mathrm{N}_{2}$ is important. Nitrogen has strong dipole-allowed transitions at wavelengths shorter than 100 $\mathrm{nm}$. In the wavelength region studied here only symmetry-forbidden and consequently weak transitions have been reported. More specifically, in the $200 \mathrm{~nm}$ region the $(0,0)$ origin band of the Vegard-Kaplan system is located. However, the oscillator strength of this $A^{3} \Sigma_{u}^{+}-X^{1} \Sigma_{g}^{+}$spin forbidden system is small, and in addition the Franck-Condon factor of the $(0,0)$ band is very weak. Consequently, the absorption cross section is expected to be well below the Rayleigh scattering value, i.e. the extinction behavior should be fully Rayleigh dominated.

Information on the optical extinction behavior of the greenhouse gas $\mathrm{CH}_{4}$ around 200 $\mathrm{nm}$ is largely lacking. So far only absorption studies have been reported for a series of temperatures in the 106 to $145 \mathrm{~nm}$ region $[8,9]$ and more recently theoretical results on the photodissociation of $\mathrm{CH}_{4}$ around $124 \mathrm{~nm}$ has been reported [10]. Toward longer wavelengths experimental studies are lacking.

Sulphur hexafluoride is an atmospheric trace gas that is primarily of anthropogenic origin but also occurs naturally. It is highly stable, the reason why it is used in a number of 
industrial applications, which may have caused an atmospheric $\mathrm{SF}_{6}$ increase of $0.24 \mathrm{ppt}$ in the early 1970 s to nearly $4 \mathrm{ppt}$ at the end of the $20^{\text {th }}$ century [11]. Deep-UV absorption spectra of $\mathrm{SF}_{6}$ have been recorded in the $78-185 \mathrm{~nm}$ region $[12,13]$, but information on the light extinction at longer wavelengths is essentially lacking.

In this paper an experimental study of the optical extinction behavior of $\mathrm{N}_{2}, \mathrm{CH}_{4}$ and $\mathrm{SF}_{6}$ in the $198-270 \mathrm{~nm}$ region is presented. This is achieved by combining highly sensitive cavity ring-down spectroscopy (CRDS) and the so called pressure ramp technique that allows unraveling the linear extinction signal associated with molecular scattering. In the next section, first the analytical approach is described, followed by experimental details. The results are discussed within the context of existing literature values. In the conclusion the main points are summarized.

\section{Analytical approach}

Rayleigh scattering [14], being considered in terms of classical electrodynamics theory $[15,16]$, originates from the secondary radiation of oscillating electric dipoles, induced by an electric field from the incident light. Consequently, the Rayleigh scattering cross section $\sigma_{\mathrm{R}}$ can be defined in two ways, either via molecular volume polarizability $\alpha_{v o l}$

$$
\sigma_{R}=\frac{128}{3 \lambda^{4}} \pi^{5} \alpha_{v o l}^{2}
$$

or, more conveniently, via $[17,18]$ :

$$
\sigma_{R}=\frac{24 \pi^{3}}{\lambda^{4} N^{2}}\left(\frac{n(\lambda)^{2}-1}{n(\lambda)^{2}+2}\right)^{2} F_{k}(\lambda),
$$

where $\lambda$ is the wavelength in $\mathrm{cm}, N$ is the density of the molecules in $\mathrm{cm}^{-3}$ and $n(\lambda)$ is the wavelength dependent refractive index. This convention is used throughout this work. The Rayleigh formula (Eq. 2) relates the scattering cross section to two directly measurable 
quantities; the refractive index and the gas density. Note that the latter two are macroscopic properties of the gas related such that $\sigma_{R}$ represents a single-particle cross section. A comparison between measurements of the Rayleigh cross section and the refractive index, for a known density, yields information on the dimensionless King correction factor $F_{k}(\lambda)$ [15]. This factor accounts for the anisotropy in scattering by non-spherical molecules, which is important for the description of polarization and angular-dependent effects and is defined by

$$
F_{k}(\lambda)=\frac{3+6 \rho_{p}(\lambda)}{3-4 \rho_{p}(\lambda)}=\frac{6+3 \rho_{n}(\lambda)}{6-7 \rho_{n}(\lambda)} .
$$

Here $\rho_{\mathrm{p}}$ and $\rho_{\mathrm{n}}$ stand for the depolarization ratio of either polarized or natural (unpolarized) incident light, respectively, which is specified in Refs. [16, 19, 20, 21]. The role of molecular polarization effects becomes significantly stronger in the deep UV compared to the visible. Consequently, the depolarization ratio of investigated molecular species must be taken into account as well [22].

\section{Experiment}

The experimental setup and approach to measure Rayleigh scattering cross sections have been described in detail previously $[6,23,24]$ and are based upon direct absorption spectroscopy applying CRDS. Pulsed laser radiation is obtained by frequency doubling of the blue-green output of a Spectra Physics PDL-2 dye laser (operated on Coumarin 152, Coumarin 307 and Stilbene 3 laser dyes), pumped by a $355 \mathrm{~nm} \mathrm{Nd:YAG} \mathrm{laser} \mathrm{at} 10 \mathrm{~Hz}$ repetition rate, yielding wavelengths at 270.15, 251.72, 215.38 and $210.12 \mathrm{~nm}$. Wavelengths at 203.76, 199.27, 198.48 and $197.70 \mathrm{~nm}$ are generated by frequency-tripling the output of a pulsed (SIRAH) dye laser, running near $600 \mathrm{~nm}$ on Rhodamine-B dye and pumped by a Nd:YAG laser at $532 \mathrm{~nm}$, also at $10 \mathrm{~Hz}$ repetition rate. The final band width, in both configurations, is better than $0.2 \mathrm{~cm}^{-1}$ and the absolute accuracy of the wavelength calibration, performed by an echelle-grating spectrometer, is of the order of $0.01 \mathrm{~nm}$. 
The laser light is focused into an optical cavity comprising of two highly reflective mirrors and the light leaking out is detected by a photo-multiplier tube (Hamamatsu H9858 series) and subsequently digitized by a LeCroy9450 $350 \mathrm{MHz}$ oscilloscope. The reflectivity of the CRD mirrors $\left(\mathrm{r}_{\text {curv }}=25 \mathrm{~cm}\right)$ is better than $99.4 \%$ in the $215.38-270.15$ $\mathrm{nm}$ region and $\sim 98 \%$ at $210.12 \mathrm{~nm}$. These mirrors are mounted onto a $40 \mathrm{~cm}$ long cell, resulting in decay times of about $250 \mathrm{~ns}$ ( $5 \%$ uncertainty). High-quality mirrors $\left(\mathrm{r}_{\text {curv }}=1\right.$ m) have been obtained (from LaserOptik) with an effective reflectivity of $99.2 \%$ in the 198-201 nm region; this constitutes a major improvement over previous deep-UV CRDS experiments [25]. The mirrors are mounted onto an $82 \mathrm{~cm}$ long cell, previously designed for pressure ramp CRDS studies [24]. This cell contains a multitude of inlet holes for the gas to enter the scattering region, while avoiding turbulence effects. The pressure in both cells is measured with high precision (0.15\%) using an Edwards type 600AB Baratron. Pressure ramps are used to separate the molecular extinction signal from cavity losses and to extract absolute absorption cross sections [23]. For this both the pressure and the decay time of the cavity are continuously monitored, while gradually increasing the gas density in the scattering region.

The decay rate $\beta$ obtained in this CRDS measurement, equaling the inverse of the ring down decay time $\tau$, scales with the gas density

$$
\beta=\frac{c|\ln R(\lambda)|}{d}+c \sigma N .
$$

Hence, from a series of measurements at fixed wavelength and at increasing gas density $\mathrm{N}$, both the averaged reflectivity $\mathrm{R}(\lambda)$ of the mirror set and the absolute extinction cross section $\sigma$ can be obtained. Note that the latter follows from the slope of each $\beta$ vs. $\mathrm{N}$ measurement and that the resulting value is independent of the cell length d. CRDS pressure ramp scans have been recorded in pressure ranges up to atmospheric pressure. At every momentary pressure value, five decay transients are digitized and fitted. The slope coefficient of each individual pressure ramp measurement is determined with an accuracy of a few percent. The resulting cross-section values over the entire set of measurements are 
spread over a relatively large range and therefore a significant number of pressure ramp scans (typically 10) has been taken to statistically decrease the experimental error. All measurements have been taken at $293 \pm 3 \mathrm{~K}$.

High purity gases are used $\left(99.999 \%\right.$ for $\mathrm{N}_{2}, 99.995 \%$ for $\mathrm{CH}_{4}$ and $99.8 \%$ for $\mathrm{SF}_{6}$ ) and a 0.5 micron filter cleans the injected gas from dust and aerosol particles, which may affect the scattering properties of the gas. It should be noted that the laser wavelength is not scanned during subsequent gas fillings, as only for fixed wavelengths frequency-dependent baseline fluctuations can be excluded. This also explains why only a limited number of frequency measurements is presented here, well distributed over the region of interest.

\section{$\underline{\text { Results and discussion }}$}

The resulting extinction curves for $\mathrm{N}_{2}, \mathrm{CH}_{4}$ and $\mathrm{SF}_{6}$ are shown in Figs. 1, 3 and 5, respectively. In Table 1 the measured and predicted extinction cross sections (with $1 \sigma$ uncertainties) are listed using Eq. (2). These predicted values are calculated to equal the Rayleigh scattering cross-section values, and hence it is assumed that no absorption occurs. Formulas for the refractive indices and for the King correction factor are taken from the literature and extrapolated to the deep-UV region, if necessary.

It should be noted that due to the wavelength dependence of the refractive index and the King correction factor, the Rayleigh scattering cross section is not exactly proportional to $1 / \lambda^{4}$. Consequently, a proper mathematical function accounting for this difference, see Ref. [26], has to be used as demonstrated previously [6, 23, 24],

$$
\sigma_{R}=\sigma v^{(4+\varepsilon)}
$$

where $v$ is the light frequency in $\mathrm{cm}^{-1}$. Hence the wavelength-dependent Rayleigh scattering $\sigma_{\mathrm{R}}$ is expressed in terms of two variables $\sigma$ and $\varepsilon$. In this functional representation is $\varepsilon$ a dimensionless parameter and the dimension of $\sigma$ consequently depends on the value of $\varepsilon$. In the following this is not addressed further. A simultaneous fit of both variables results in large error margins because of a strong correlation. Therefore a two step fitting procedure has been applied: the $\sigma$ parameter is kept fixed to the predicted and 
uncorrected theoretical value (calculated from the refractive index and the King correction factor), while the value for $\varepsilon$ is repeatedly optimized. During the second step free and fixed parameters are interchanged and statistically reliable values are found after a few iterations. The experimental and predicted values for the three gases studied here are given in Table 2.

\section{$\underline{\text { Molecular nitrogen }}$}

Accurate information (with an uncertainty of about $2 \times 10^{-5}$ percent) of the $\mathrm{N}_{2}$ refractive index behavior in the $145-270 \mathrm{~nm}$ region is available for $273.15 \mathrm{~K}$ and $101325 \mathrm{~Pa}$ from Refs. [27, 28]. To convert the refractive index data from Ref. [28] to the present laboratory conditions (293 K, similar pressure) the following equation is used [28, 29];

$$
\frac{n_{1}-1}{n_{2}-1}=\frac{P_{1} T_{2} Z_{2}}{P_{2} T_{1} Z_{1}}\left(1+\frac{n_{1}}{6}\left(1-\frac{P_{2} T_{1}}{P_{1} T_{2}}\right)\right)
$$

with $n_{i}$ the refractive index at pressure $P_{i}[\mathrm{~Pa}]$ and temperature $T_{i}[K]$ and where $Z$, the value of gas compressibility is given by [28, 29]

$$
Z_{i}=1-\frac{P_{i}}{101325}\left(317.6-T_{i}\right) \times 10^{-5}
$$

In this way 31 measured values of refractive indices $n_{i}\left(\lambda_{i}\right)$ [28] were scaled to $293 \mathrm{~K}$ and $101325 \mathrm{~Pa}$ and then fitted to a two term Sellmeier formula [30], resulting in the dispersion relationship;

$$
n(\lambda)-1=\left(\frac{3.635 \cdot \lambda^{2}}{43.878 \times 10^{-5} \cdot \lambda^{2}-1}+\frac{0.0261 \cdot \lambda^{2}}{0.134 \times 10^{-5} \cdot \lambda^{2}-1}\right) \times 10^{-8} .
$$

The absolute uncertainty achieved during the fit is better than $0.1 \%$. This determines the final uncertainty in the dispersion formula, since the error of the measured values of the refractive index is much smaller.

The King correction factor for the $200-632.8 \mathrm{~nm}$ region is available with an uncertainty better than one percent from Ref. [27] and given in Eq. (9); 


$$
F_{k}(\lambda)=1.03+\frac{3.17 \times 10^{-12}}{\lambda^{2}} .
$$

Seven data points for the wavelength dependent Rayleigh cross section of $\mathrm{N}_{2}$ are indicated in Fig. 1a. The points follow a dashed line that represents the prediction of the Rayleigh scattering cross section based on dispersion relationships, given by Eqs. (8) and (9). The solid line in Fig. 1a represents the fit for the resulting $\sigma=1.80 \times 10^{-46}$ and $\varepsilon=$ 0.543 values as listed in Table 2. The difference between the calculated and predicted values and the corresponding uncertainty range by the present fit representation is plotted in the lower graph (Fig. 1b). All values overlap within their uncertainties, with exception of the $270.15 \mathrm{~nm}$ results. This may be due to the relatively low experimental sensitivity at this wavelength.

Since $\mathrm{N}_{2}$ is a non-spherical molecule significant depolarization effects are expected in the deep-UV domain. To estimate how strong these effects are, a further quantitative analysis of the experimental data set has been performed and refractive index and King correction factor values have been derived using the current fit representation, as defined in Eq. (5). The King correction factor values are derived using Eq. (2), assuming that the refractive index dispersion is equal to Eq. (8). A similar approach has been used to calculate the refractive index values for $\mathrm{N}_{2}$, using Eq. (9). The molecular volume polarizability values have been calculated directly from Eq. (1), assuming that the Rayleigh scattering cross sections are equal to those predicted by the fit representation as given by Eq. (5). The values of the depolarization ratio for polarized light have been calculated using Eq. (3). The resulting values for $F_{k}{ }^{\exp }(\lambda), n^{\exp }(\lambda), \alpha_{\text {vol }} \exp ^{\operatorname{ex}}(\lambda)$ and $\rho_{p}{ }^{\exp }(\lambda)$ are plotted in Figs. 2a through d, respectively (see figure caption for detailed information). In all cases the confidence intervals that are based on the experimental uncertainties are plotted as well. This shows that the values calculated from the fit representation using the measured Rayleigh scattering cross sections are in good quantitative agreement (within the specified uncertainty) with data available from literature [7, 27, 28,]. The deviation between the calculated values of the King correction factor, refractive index, molecular 
volume polarizability and the depolarization ratio becomes smaller towards $300 \mathrm{~nm}$. It should be noted that the difference between values of the King correction factor, derived from the present Rayleigh scattering cross-section determinations and the values, available from Ref. [27] is larger than that of the refractive index data. This is also reflected in the discrepancy between calculated and theoretical values of the molecular volume polarizability and the depolarization ratio. The reason for this is a general lack of depolarization measurements in the deep-UV domain (shorter than $300 \mathrm{~nm}$ ).

The outcome confirms that the light extinction in the deep UV for $\mathrm{N}_{2}$ is fully determined by Rayleigh scattering and that there is no evidence for a (detectable) absorption onset in the studied wavelength region.

\section{Methane}

Six data points for the wavelength dependent Rayleigh cross section of $\mathrm{CH}_{4}$ were measured and are plotted in Fig. 3. Methane refractive index data have been reported only in the interval between 325.13 and $632.99 \mathrm{~nm}$, based on the polarizability measurements given in Ref. [31]. Other information, particularly depolarization measurements, is largely lacking. A comparison with the depolarization effects for the symmetrically comparable $\mathrm{CCl}_{4}$ at $632.8 \mathrm{~nm}$ suggests that these are small [16] and it seems reasonable to set $F_{k}(\lambda)=1$ for methane. The dispersion formula for the refractive as extracted in Ref. [24] from the experimental data in Ref. [31] is used to calculate the Rayleigh scattering cross sections.

$$
n(\lambda)-1=\left(46662+\frac{4.02 \times 10^{-6}}{\lambda^{2}}\right) \times 10^{-8} .
$$

In view of the very limited number of refractive index measurements the accuracy of this equation is assumed to be on the level of 4\% [24]. Extrapolation to the deep UV, as necessary here, most likely gives rise to additional uncertainty.

The values that result from the extinction measurements are plotted in Fig. 3a. For a quantitative estimate of the difference between the measured and predicted $\sim 1 / \lambda^{4}$ Rayleigh scattering behavior in $\mathrm{CH}_{4}$ (based on dispersion), a non-linear least square fit along Eq. (5) 
has been made that is included in Fig. 3 as well. The resulting values for $\sigma$ and $\varepsilon$ are listed in Table 2. The discrepancy between the dispersion-related and CRDS derived cross sections is below $10 \%$ (Fig. 3b).

As for molecular nitrogen values for the refractive index and the molecular volume polarizability have been derived for methane. For this depolarization effects are neglected and $F_{k}(\lambda)=1$ is taken for all wavelengths. The resulting curves for the refractive index and molecular volume polarizability are plotted in Figs. 4a and 4b. The estimated discrepancy between the calculated and predicted values of the refractive index values is less than $6 \%$ (Fig. 4c), originating from inaccuracies in the CRDS measurements and from the extrapolation of the dispersion formula for the refractive index in $\mathrm{CH}_{4}$. This is comparable with the absolute uncertainty of the dispersion formula of $\sim 4 \%$ in the $325-632 \mathrm{~nm}$ region $[24,31]$. Also here, the outcome confirms that the deep-UV light extinction is fully governed by Rayleigh scattering and that the refractive index in $\mathrm{CH}_{4}$ in the deep-UV domain can be described by the dispersion relationship in form of Eq. (10) within a few percent uncertainty. The molecular volume polarizability values, calculated from the present CRDS measurements are found to be in a good agreement with the data available from Ref. [32].

It is important to note that the purity of the $\mathrm{CH}_{4}$ gas used is critical. In a first set of measurements with purity less than $99.5 \%$ and most likely hydrocarbon-like impurities an absorption onset was found around $\sim 210 \mathrm{~nm}$ that definitely cannot be attributed to methane.

\section{Sulphur hexafluoride}

In Fig. 5 the data point set for the wavelength dependent Rayleigh cross section of $\mathrm{SF}_{6}$ is shown. In the literature a limited data set of $\mathrm{SF}_{6}$ refractive indices and extinction coefficient measurements have been reported $[12,13,24]$. Sulphur hexafluoride is a highly symmetrical molecule, so $F_{k}(\lambda)=1$ is used. The derived empirical formula for dispersion 
of the refractive index, based on measurements at 633 and $1300 \mathrm{~nm}$ [33] has been used in the UV-VIS [23, 24, 25]:

$$
n(\lambda)-1=\left(71517+\frac{5 \times 10^{-6}}{\lambda^{2}}\right) \times 10^{-8} .
$$

The data points follow a dashed line that represents predictions of Rayleigh scattering cross-section values based on available dispersion data, as can be seen in Fig. 5. This line coincides with a solid line that is the fit representation for $\sigma=17.90 \times 10^{-46}$ and $\varepsilon=$ 0.490(4) as summarized in Table 2. The measured and predicted Rayleigh scattering cross sections agree within $2 \%$ for the deep-UV domain, and the overall picture indicates that light extinction in $\mathrm{SF}_{6}$ gas is governed by Rayleigh scattering in the entire studied wavelength interval.

Additional information is available from Fig. 6 that shows the refractive index (solid black line in Fig. 6a) and the molecular volume polarizability (solid line in Fig. 6b) values, derived from the fit representation of the measured Rayleigh scattering cross-section values. The dashed lines in Fig. 6 show the predicted values derived from the Rayleigh scattering cross section, based on dispersion data available from literature [24].

The comparison made for calculated molecular volume polarizability values shows that $\mathrm{SF}_{6}$ has the largest polarizability among all investigated gas species. The error margins that originate from the absolute uncertainty of the $\sigma$ and $\varepsilon$ values are shown as grey solid lines in Fig. 6 as well. The literature values [24, 33] are indicated for comparison. From the numerical analysis it can be concluded that despite the lack of laboratory data, the refractive index of $\mathrm{SF}_{6}$ follows the dispersion formula, given by Eq. (11), within a few percent uncertainty, even when extrapolated to the deep UV.

\section{Conclusions}

Extinction coefficients have been measured for gaseous $\mathrm{N}_{2}, \mathrm{CH}_{4}$ and $\mathrm{SF}_{6}$ at room temperature between 197.7 and $270.15 \mathrm{~nm}$ applying cavity ring down spectroscopy to 
pressure ramp measurements. A non-linear squares fit of a $\sim 1 / \lambda^{4}$ like function shows the actual behavior of the Rayleigh scattering and gives an estimate of the discrepancy between measured and predicted values, based on dispersion formulas as available from literature. The light extinction in the deep UV is for all three molecular systems dominated by Rayleigh scattering. Due to the present lack of experimental data for light extinction cross sections and refractive indices between the deep UV and visible domain, it is not yet possible to construct a universal empirical relation that accurately predicts the $1 / \lambda^{4}$ Rayleigh scattering behavior for the entire UV-VIS region.

\section{$\underline{\text { Acknowledgments }}$}

The authors thank J. Bouma for technical support and the Netherlands Foundation for Fundamental Research (FOM) for financial support via their Molecular Atmospheric Physics (MAP) program. 


\section{$\underline{\text { References }}$}

1. H. Horvath, Atmospheric Environment, 27A, 293 (1993).

2. R.R. Meier, G. P. Anderson, C. A. Cantrell, L. A. Hall, J. Lean, K. Minschwaner, R. E. Shetter, E. P. Shettle and K. Stamnes, J. Atmos. Solar-Terrestr. Phys., 59, 2111 (1997).

3. A. C. Eckbreth: Laser Diagnostics for Combustion Temperature and Species (Abacus, Cambridge, MA 1988).

4. D. E. Shemansky, J. Chem. Phys. 56, 1582 (1972).

5. A. Karaiskou, C. Vallance, V. Papadakis, I. M. Vardavas, T. P. Rakitzis, Chem. Phys. Lett. 400, 30 (2004).

6. D. Ityaksov, H. Linnartz, W. Ubachs, Chem. Phys. Lett. 462, 31 (2008).

7. W. Reckers, Y. Gu, E. W. Rothe and H. Voges, Appl. Spectr. 51, 1012 (1997).

8. L. C. Lee, C.C. Chiang, J. Chem. Phys. 78, 688 (1983).

9. F. Z. Chen, C. Y. R. Wu, J. Quant. Spectrosc. Radiat. Transfer, 85, 195 (2004).

10. R. van Harrevelt, J. Chem. Phys. 126, 204313 (2007).

11. M. Maiss, A. M. Brenninkmeijer, Environ. Sci. Technol. 32, 3077 (1998).

12. E. D. Nostrand, A. B. F. Duncan, J. Am. Chem. Soc. 76, 3377 (1954).

13. C. Pradayrol, A. M. Casanovas, I. Deharo, J. P. Guelfucci, J. Casanovas, J. Phys. III France 6, 603 (1996).

14. J. W. Strutt, Philos. Mag. 47, 375 (1899).

15. L. V. King, Proc. Roy. Soc. (London) 104, 333 (1923).

16. N. J. Bridge, A. D. Buckingham, Proc. Roy. Soc. (London) A295, 334 (1966).

17. A. Bucholtz, Appl. Opt. 34, 2765 (1995).

18. C. M. Penney, J. Opt. Soc. Am. 59, 34 (1969).

19. J. Oddershede, E. N. Svendsen, Chem. Phys. 64, 359 (1982).

20. E. Dayan, J. Chem. Soc. Faraday Trans. II, 76, 309 (1980).

21. J. A. Sutton, J. F. Driscoll, Opt. Lett. 29, 2620 (2004). 
22. M. P. Bogaard, A. D. Buckingham, R. K. Pierens and A. H. White, J. Chem. Soc. Faraday Trans., 74, 3008 (1978).

23. H. Naus, W. Ubachs, Opt. Lett. 25, 347 (2000).

24. M. Sneep, W.Ubachs, J. Quant. Spectrosc. Radiat. Transfer, 92, 293 (2005).

25. M. Sneep, S. Hannemann, E. J. van Duijn, W. Ubachs, Opt. Lett. 29, 1378 (2004).

26. P. M. Teillet, Appl. Opt. 29, 1897 (1990).

27. D. R. Bates, Planet. Space Sci. 32, 785 (1984).

28. U. Griesmann, J. H. Burnett, Opt. Lett. 24, 1699 (1999).

29. E. R. Peck, B.N. Khanna, J. Opt. Soc. Am. 56, 1059 (1966).

30. B. Tatian, Appl. Opt., 23, 4477 (1984).

31. U. Hohm, Mol. Phys. 78, 929 (1993).

32. A. Koch, H. Voges, P. Andersen, H. Schuter, D. Wolff, W. Hentschel, W. Oppermann, E. Rothe, Appl. Phys. B 56, 177 (1993).

33. D. Vukovic, G. A. Woolsey, G. B. Scelsi, J. Phys. D 29, 634 (1996).

34. Landolt-Bornstein: Zahlenwerte und Funktionen, $6^{\text {th }}$ ed. (Springer Berlin, Heidelberg, 1962) Vol. II, part 8, Optische Konstanten. 


\section{Table 1}

Measured and predicted light extinction cross-section values in the $197.7-270.15 \mathrm{~nm}$ region for $\mathrm{N}_{2}, \mathrm{CH}_{4}$ and $\mathrm{SF}_{6}$, obtained from $\mathrm{CRD}$ pressure ramp measurements.

\begin{tabular}{|c|c|c|c|c|c|c|}
\hline \multirow{2}{*}{$\lambda[\mathrm{nm}]$} & \multicolumn{6}{|c|}{ Extinction cross section/ $10^{-25}\left[\mathrm{~cm}^{2}\right]$} \\
\cline { 2 - 7 } & \multicolumn{2}{|c|}{$\mathrm{N}_{2}$} & \multicolumn{2}{|c|}{$\mathrm{CH}_{4}$} & \multicolumn{2}{|c|}{$\mathrm{SF}_{6}$} \\
\cline { 2 - 7 } & measured & predicted $^{a, b, e}$ & measured & predicted $^{c, e}$ & measured & predicted \\
\hline 197.70 & $3.39 \pm 0.30$ & $3.62 \pm 0.09$ & $11.92 \pm 0.64$ & $10.82 \pm 0.03$ & $26.86 \pm 2.54$ & 23.71 \\
\hline 198.48 & $3.60 \pm 0.18$ & $3.55 \pm 0.08$ & $12.59 \pm 1.30$ & $10.62 \pm 0.03$ & $19.35 \pm 2.22$ & 23.28 \\
\hline 199.27 & $4.22 \pm 0.80$ & $3.48 \pm 0.08$ & $11.09 \pm 2.42$ & $10.43 \pm 0.03$ & $20.68 \pm 2.14$ & 22.86 \\
\hline 203.76 & $3.38 \pm 0.59$ & $3.14 \pm 0.08$ & & $9.39 \pm 0.02$ & & 20.64 \\
\hline 210.12 & & $2.7 \pm 0.1$ & & $8.13 \pm 0.02$ & $18.33 \pm 4.04$ & 17.94 \\
\hline 215.38 & $2.61 \pm 0.42$ & $2.43 \pm 0.06$ & $7.79 \pm 1.25$ & $7.25 \pm 0.02$ & $16.09 \pm 2.59$ & 16.04 \\
\hline 251.72 & $1.33 \pm 0.10$ & $1.21 \pm 0.03$ & $3.56 \pm 0.2$ & $3.57 \pm 0.01$ & $8.06 \pm 1.35$ & 8.00 \\
\hline 270.15 & $1.17 \pm 0.17$ & $0.89 \pm 0.02$ & $2.53 \pm 0.33$ & $2.61 \pm 0.01$ & $5.98 \pm 0.40$ & 5.88 \\
\hline
\end{tabular}

${ }^{a)}$ Dispersion relationship, derived from refractive index measurements in Ref. [28].

${ }^{b)}$ Dispersion formula for King correction factor, available from Ref. [27].

c), d) Dispersion relationships for the refractive indices, available from Ref. [24].

e) The absolute error values given here are derived from the uncertainties of the King correction factor and the refraction index dispersion relationships. For $\mathrm{SF}_{6}$ the latter is not available, which is the reason why in the last column no error values can be listed. 


\section{Table 2.}

Results of a non-linear square fit of Eq. (5) to the experimental data points, both from the present work and from literature, for $\mathrm{N}_{2}, \mathrm{CH}_{4}$ and $\mathrm{SF}_{6}$ gas.

\begin{tabular}{|c|c|c|c|c|c|}
\hline \multirow{3}{*}{ Gas } & \multicolumn{4}{|c|}{ Fit representation } & \multirow{2}{*}{$\begin{array}{c}\text { Wavelength interval } \\
{[\mathrm{nm}]}\end{array}$} \\
\cline { 2 - 5 } & \multicolumn{2}{|c|}{$\sigma\left[10^{-46}\right]$} & \multicolumn{2}{|c}{$\varepsilon$} & \\
\cline { 2 - 5 } & experimental $^{\text {predicted }}{ }^{a}$ & experimental & predicted $^{a}$ & \\
\hline $\mathrm{N}_{2}$ & $1.80 \pm 0.06$ & 1.796 & $0.534 \pm 0.003$ & 0.529 & $197.70-270.15$ \\
\hline $\mathrm{CH}_{4}$ & $0.94 \pm 0.02$ & 0.942 & $0.699 \pm 0.002$ & 0.689 & $197.70-270.15$ \\
\hline $\mathrm{SF}_{6}$ & $17.90 \pm 0.76$ & 17.897 & $0.490 \pm 0.004$ & 0.490 & $197.70-270.15$ \\
\hline
\end{tabular}

${ }^{a}$ Values for $\sigma$ and $\varepsilon$, derived from the fit, performed to predicted (dispersion-based) values of Rayleigh scattering cross section. 


\title{
Figure Captions
}

\begin{abstract}
Figure 1.
a: The Rayleigh scattering cross-section behavior of $\mathrm{N}_{2}$ derived from a combined CRD - pressure ramp experiment (black circles). The dashed line represents the Rayleigh scattering cross-section values, calculated from dispersion data for refractive indices taken from Ref. [28] and for a King correction factor as used in Ref. [27]. The solid line shows the fit representation for $\sigma=1.80(6) \times 10^{-46}$ and $\varepsilon=0.534$ (3).

b: The difference between calculated (from the dispersion) and fitted (from CRDS measurements) values, plotted as a solid line. The dashed lines indicate the confidence interval, based on the uncertainties of $\sigma$ and $\varepsilon$ (Table 2).
\end{abstract}

Figure 2. Different comparisons between the present experimental results and previous dispersion data:

a: The calculated behavior of the $\mathrm{N}_{2}$ King correction factor: the black dashed line follows Eq. (9) [27] and the thin dashed lines indicate the corresponding error margins. The solid black line is calculated from the present Rayleigh scattering cross-section measurements and the refractive index values, given by Eq. (8). Error margins are again plotted as thin solid lines.

b: The calculated behavior of the $\mathrm{N}_{2}$ refractive index: the black dashed line corresponds to the dispersion relationship, given by Eq. (8), open circles indicate the refractive index measurements from Ref. [28] at $273.15 \mathrm{~K}$. The black solid line corresponds to refractive index values as calculated from the present Rayleigh scattering cross-section measurements and the King correction factor, given by Eq. (9). The error margins are indicated by thin solid lines.

c: The $\mathrm{N}_{2}$ molecular volume polarizability values (black solid line), calculated from the fit representation of the present Rayleigh scattering cross-section measurements. The error margins are indicated by thin solid lines. The dashed line represents values, calculated from the dispersion formulas, Eqs. (8) and (9), for the refractive index and King correction factor. The reported results on $\alpha(\lambda)$ in Ref. [7] are indicated by solid squares.

d: The calculated values of the $\mathrm{N}_{2}$ depolarization ratio, derived from Eq. (8) for the King correction factor [27] are shown by a black dashed line. The black solid line corresponds to the calculated values, derived from the present Rayleigh scattering cross-section measurements. Error margins are shown as thin solid lines. Solid triangles correspond to direct depolarization measurements as reported in Ref. [21]. 


\section{Figure 3.}

a: The Rayleigh scattering cross-section behavior of $\mathrm{CH}_{4}$ derived from a combined CRDS - pressure ramp measurement (black circles) and the fit representation (solid line) for $\sigma=0.94(2) \times 10^{-46}$ and $\varepsilon=0.699$ (2). The dashed line represents the Rayleigh scattering cross-section values, calculated from dispersion relationships [24].

b: The difference between calculated and fitted values is shown as a black solid line. Solid thin lines indicate the error margins.

\section{Figure 4.}

a: The $\mathrm{CH}_{4}$ refractive index values, calculated from the Rayleigh scattering cross-section measurements (black solid line). The error margins are indicated by thin solid lines. The black dashed line corresponds to the dispersion formula for the refractive index, given by Eq. (10).

b: The values of the $\mathrm{CH}_{4}$ molecular volume polarizability, calculated from the present study (black solid line). The error margins are plotted as solid grey lines. The dashed line represents the calculated values, calculated from the dispersion formula for the refractive index [24]. Black squares correspond to data, calculated in Ref. [32] from results obtained in Ref. [34].

c: The discrepancy between the refractive index values, derived from the present Rayleigh scattering cross-section measurements and predicted refractive index values, using the dispersion formula as given by Eq. (10).

\section{Figure 5.}

a: The $\mathrm{SF}_{6}$ Rayleigh scattering cross-section behavior derived from a combined CRDS - pressure ramp approach (black circles) and data available from Ref. [25] (empty star). The dashed line represents the calculated Rayleigh scattering cross-section values and the solid line corresponds to the fit representation for $\sigma=17.90(76) \times 10^{-46}$ and $\varepsilon=0.490(4)$.

b: The difference between calculated and fitted values is shown as a solid black line. Solid thin lines indicate the error margins. 


\section{Figure 6.}

a: The $\mathrm{SF}_{6}$ refractive index values, calculated from the Rayleigh scattering cross-section measurements (black solid line). The error margins are given by grey solid lines. The black dashed line corresponds to the dispersion formula for the refractive index taken from Ref. [33] and given by Eq. (11) [24].

b: The molecular volume polarizability behavior, calculated from the present CRDS measurements (black solid line). The error margins are plotted as solid grey lines. The dashed line represents the calculated values, calculated from the dispersion formula for the refractive index [24].

c: The discrepancy between the refractive index values, derived from the present Rayleigh scattering cross-section measurements and the predicted values using the dispersion formula, as given by Eq. (11). 

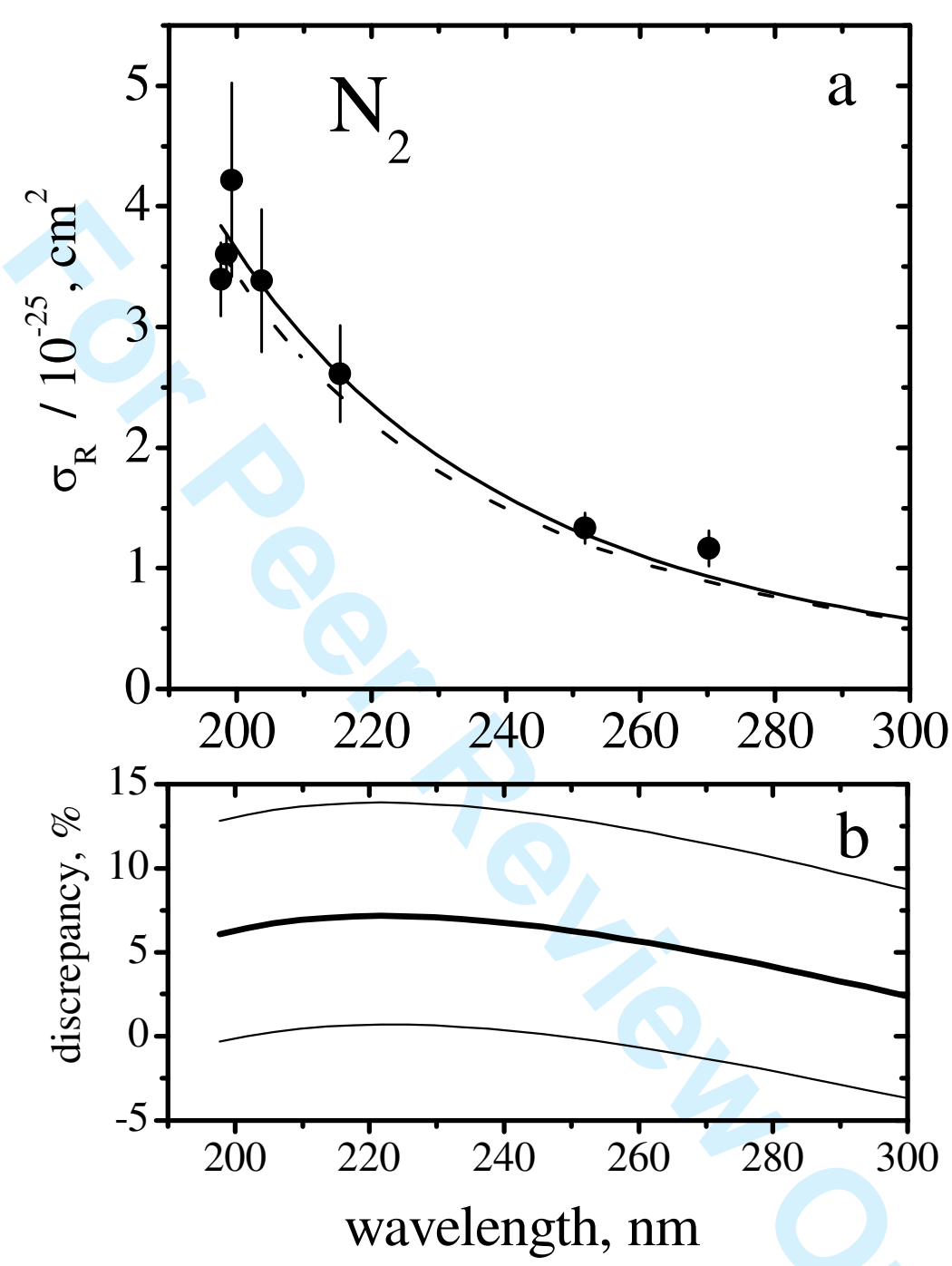

Figure 1. 

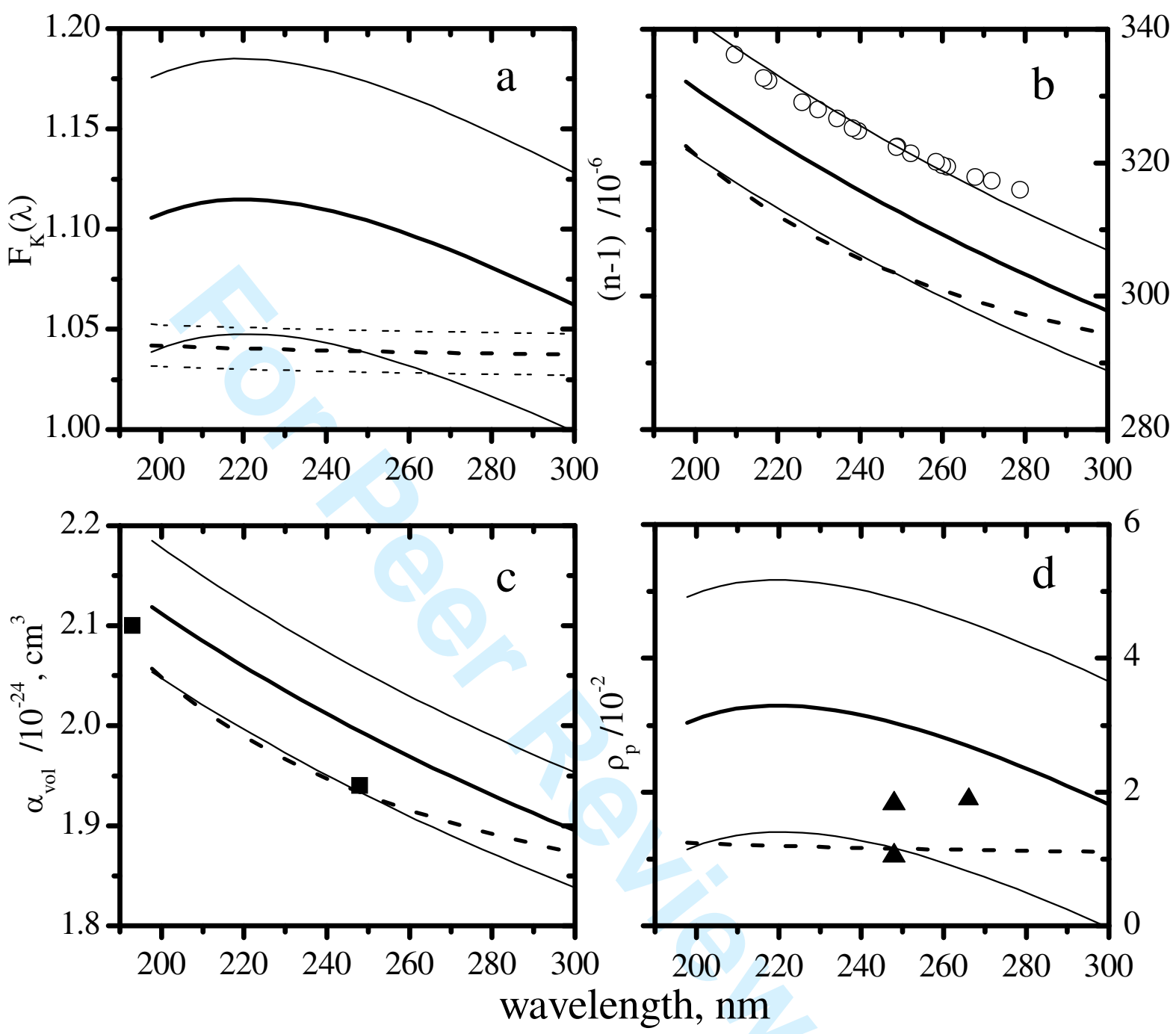

Figure 2. 

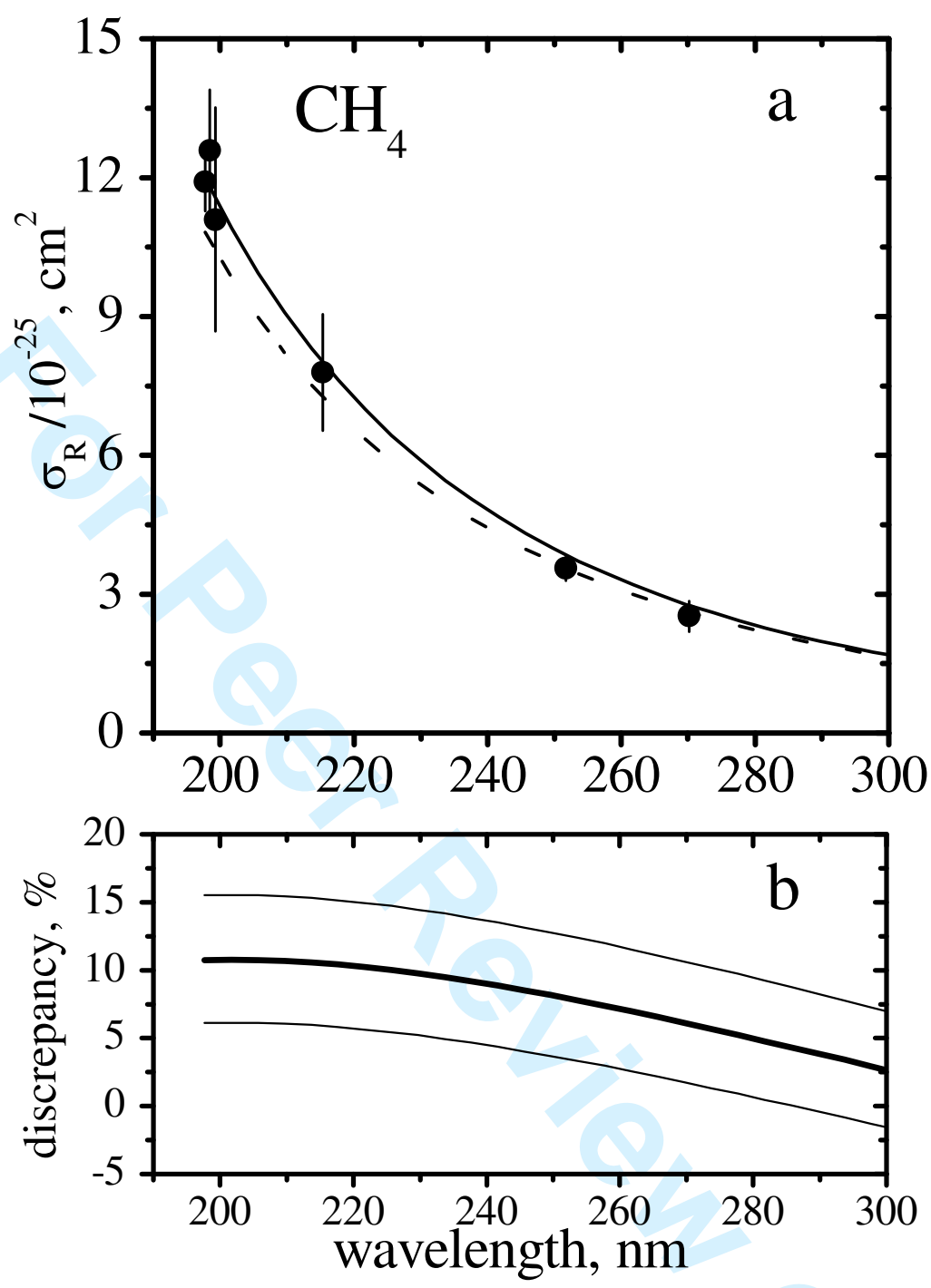

Figure 3. 

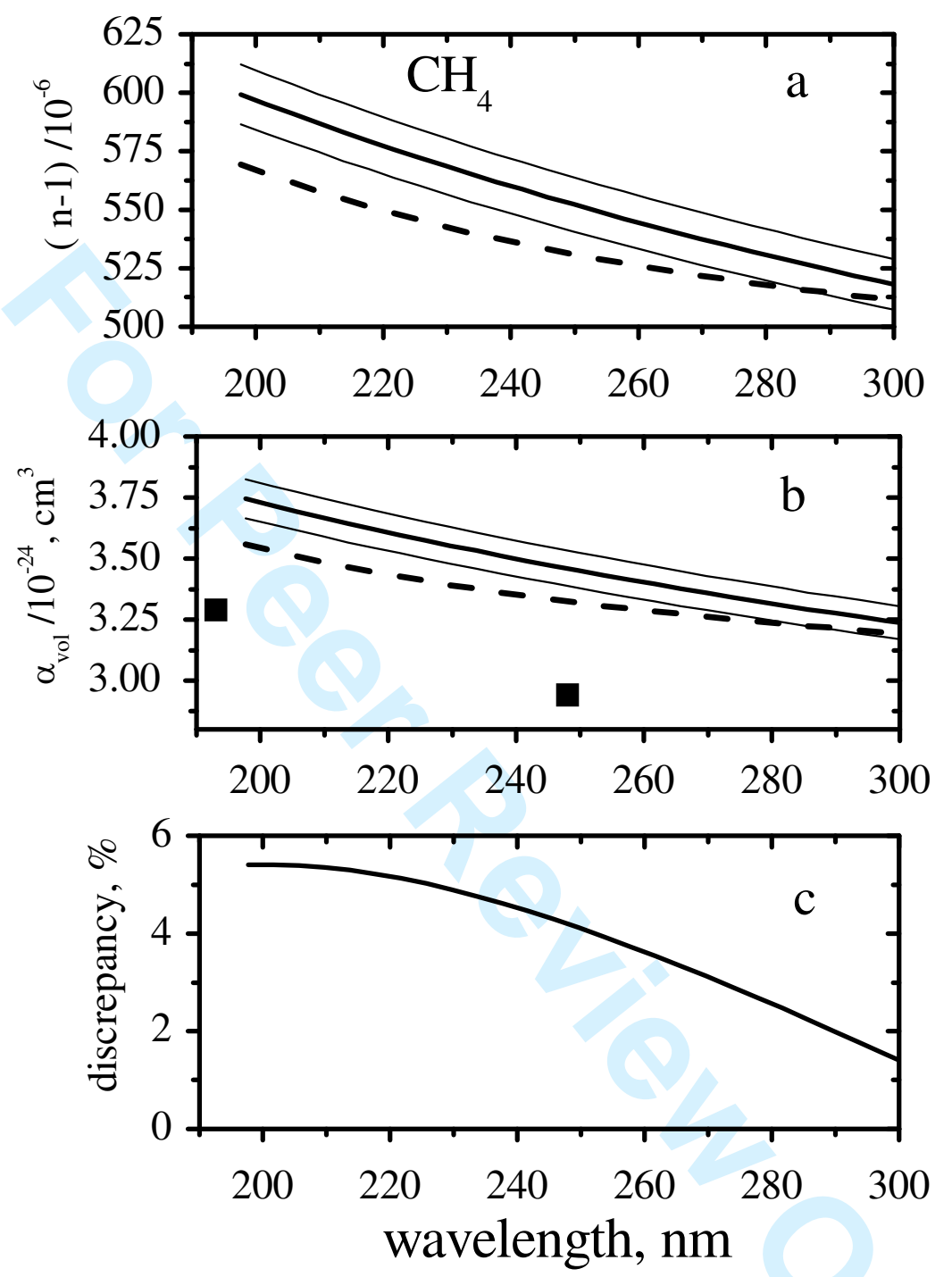

Figure 4. 


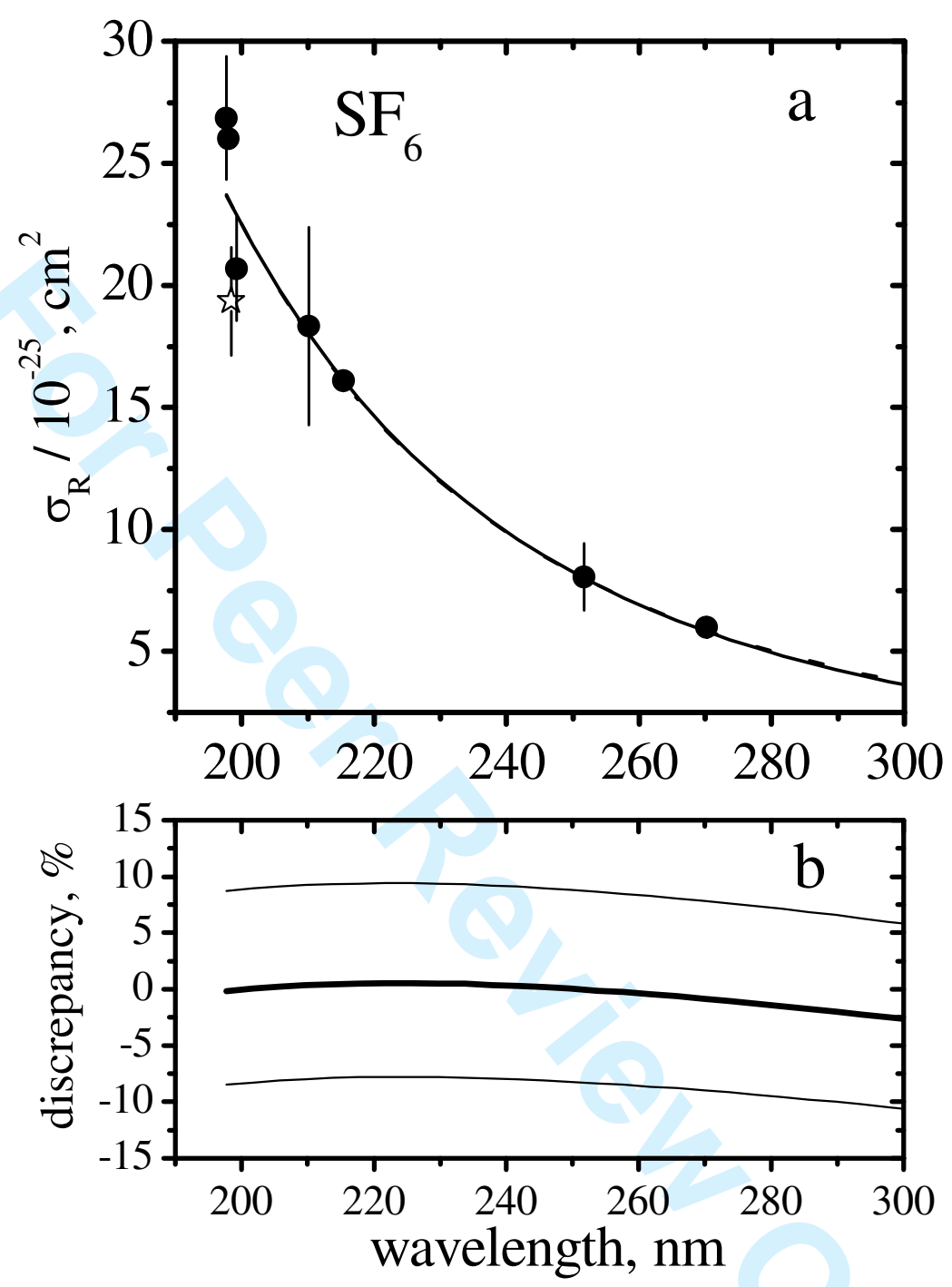

Figure 5. 

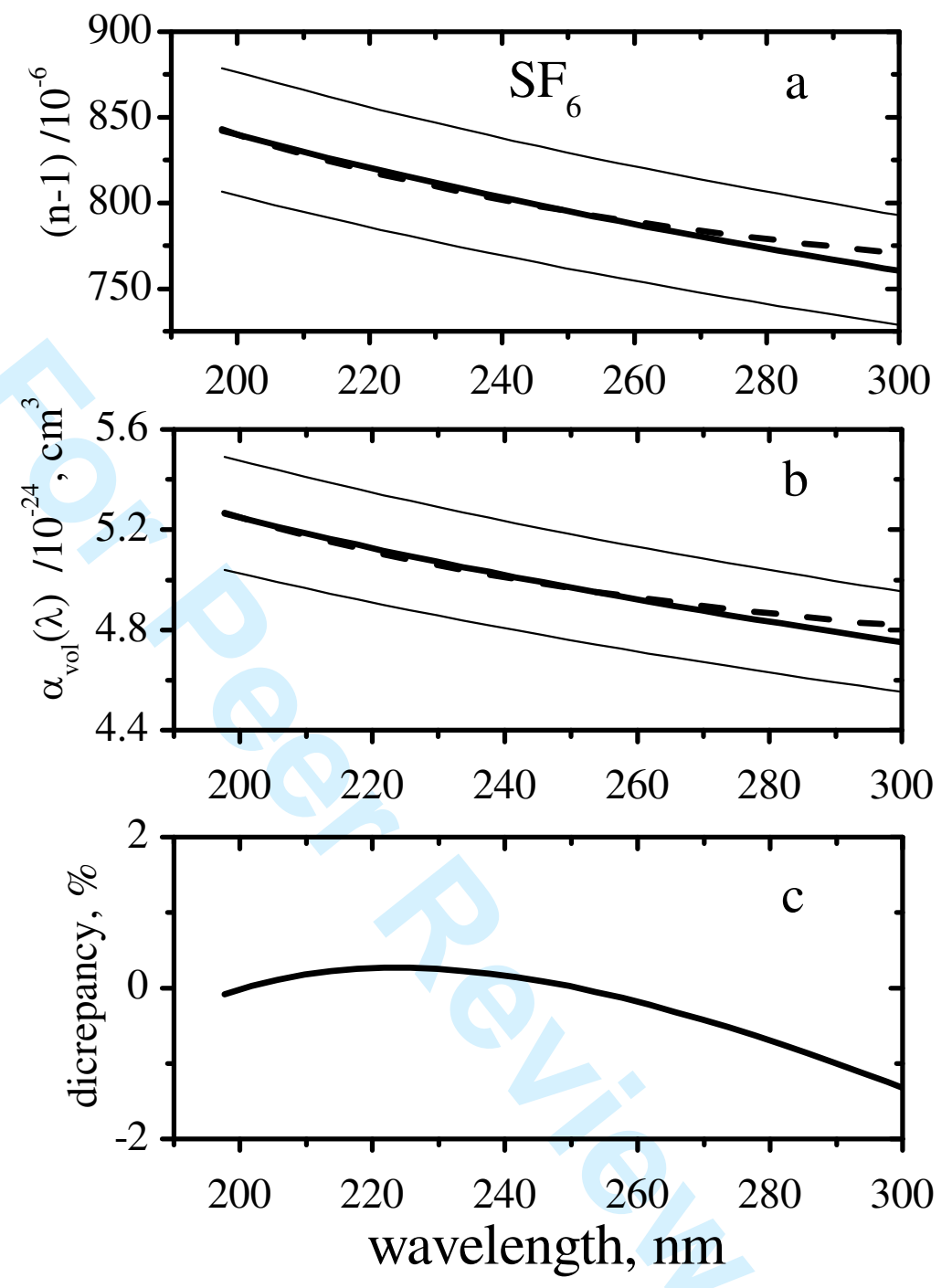

Figure 6. 


\title{
Deep-UV Rayleigh Scattering of $\mathrm{N}_{2}, \mathrm{CH}_{4}$ and $\mathrm{SF}_{6}$
}

\author{
D. Ityaksov ${ }^{1}$, H. Linnartz ${ }^{1,2}$ and W. Ubachs ${ }^{1}$ \\ ${ }^{1}$ Laser Center Vrije Universiteit, De Boelelaan 1081, NL 1081 HV Amsterdam, the Netherlands \\ ${ }^{2}$ Raymond and Beverly Sackler Laboratory for Astrophysics, Leiden Observatory, \\ University of Leiden, P.O. Box 9513, NL 2300 RA Leiden, the Netherlands
}

\begin{abstract}
$\underline{\text { Abstract }}$
Rayleigh scattering room temperature cross-section values of $\mathrm{N}_{2}, \mathrm{CH}_{4}$ and $\mathrm{SF}_{6}$ have been obtained between 198 and $270 \mathrm{~nm}$ by combining cavity ring-down spectroscopy (CRDS) and pressure ramp measurements. The experimental data have been fitted to a functional representation, describing the $\sim 1 / \lambda^{4}$ like behavior of the Rayleigh scattering cross section over a wide wavelength range. The resulting values are compared to numerical predictions, based on refractive indices and molecular anisotropy data as available from literature. From this, values of molecular volume polarizability $\alpha_{\mathrm{vol}}$ and depolarization ratios are derived. It is found that the optical extinction for all three gases is governed by Rayleigh scattering for wavelengths down to $200 \mathrm{~nm}$. No absorption onsets in the specified deep-UV region have been observed.
\end{abstract}

Keywords: Rayleigh scattering, optical extinction, cavity ring-down spectroscopy, atmospheric molecules 


\section{$\underline{\text { Introduction }}$}

Detailed information of Rayleigh scattering processes is a prerequisite to quantitatively interpret e.g. atmospheric and laser diagnostic results $[1,2,3]$. This is particularly true for deep-UV wavelengths as light scattering phenomena intensify because of the $1 / \lambda^{4}$ scaling of the Rayleigh scattering. Furthermore, optical extinction studies are important to verify whether or not constituents exhibit absorption in addition to Rayleigh scattering. The absorption onset for $\mathrm{CO}_{2}$ in the atmospherically relevant window around $200 \mathrm{~nm}$, for example, has been known for many years [4] and was studied in detail recently $[5,6]$. In laser diagnostics Rayleigh scattering cross sections are needed to determine gas density and temperature distribution, e.g. in combustion or flow media [7]. In this paper the focus is on three molecular and atmospherically relevant species: $\mathrm{N}_{2}, \mathrm{CH}_{4}$ and $\mathrm{SF}_{6}$.

Molecular nitrogen is the most abundant molecule in the Earth's atmosphere and consequently information on the absorption and scattering of UV solar radiation by $\mathrm{N}_{2}$ is important. Nitrogen has strong dipole-allowed transitions at wavelengths shorter than 100 $\mathrm{nm}$. In the wavelength region studied here only symmetry-forbidden and consequently weak transitions have been reported. More specifically, in the $200 \mathrm{~nm}$ region the $(0,0)$ origin band of the Vegard-Kaplan system is located. However, the oscillator strength of this $A^{3} \Sigma_{u}^{+}-X^{1} \Sigma_{g}^{+}$spin forbidden system is small, and in addition the Franck-Condon factor of the $(0,0)$ band is very weak. Consequently, the absorption cross section is expected to be well below the Rayleigh scattering value, i.e. the extinction behavior should be fully Rayleigh dominated.

Information on the optical extinction behavior of the greenhouse gas $\mathrm{CH}_{4}$ around 200 $\mathrm{nm}$ is largely lacking. So far only absorption studies have been reported for a series of temperatures in the 106 to $145 \mathrm{~nm}$ region $[8,9]$ and more recently theoretical results on the photodissociation of $\mathrm{CH}_{4}$ around $124 \mathrm{~nm}$ has been reported [10]. Toward longer wavelengths experimental studies are lacking.

Sulphur hexafluoride is an atmospheric trace gas that is primarily of anthropogenic origin but also occurs naturally. It is highly stable, the reason why it is used in a number of 
industrial applications, which may have caused an atmospheric $\mathrm{SF}_{6}$ increase of $0.24 \mathrm{ppt}$ in the early 1970 s to nearly $4 \mathrm{ppt}$ at the end of the $20^{\text {th }}$ century [11]. Deep-UV absorption spectra of $\mathrm{SF}_{6}$ have been recorded in the 78-185 nm region [12,13], but information on the light extinction at longer wavelengths is essentially lacking.

In this paper an experimental study of the optical extinction behavior of $\mathrm{N}_{2}, \mathrm{CH}_{4}$ and $\mathrm{SF}_{6}$ in the $198-270 \mathrm{~nm}$ region is presented. This is achieved by combining highly sensitive cavity ring-down spectroscopy (CRDS) and the so called pressure ramp technique that allows unraveling the linear extinction signal associated with molecular scattering. In the next section, first the analytical approach is described, followed by experimental details. The results are discussed within the context of existing literature values. In the conclusion the main points are summarized.

\section{Analytical approach}

Rayleigh scattering [14], being considered in terms of classical electrodynamics theory $[15,16]$, originates from the secondary radiation of oscillating electric dipoles, induced by an electric field from the incident light. Consequently, the Rayleigh scattering cross section $\sigma_{\mathrm{R}}$ can be defined in two ways, either via molecular volume polarizability $\alpha_{v o l}$

$$
\sigma_{R}=\frac{128}{3 \lambda^{4}} \pi^{5} \alpha_{v o l}^{2}
$$

or, more conveniently, via $[17,18]$ :

$$
\sigma_{R}=\frac{24 \pi^{3}}{\lambda^{4} N^{2}}\left(\frac{n(\lambda)^{2}-1}{n(\lambda)^{2}+2}\right)^{2} F_{k}(\lambda),
$$

where $\lambda$ is the wavelength in $\mathrm{cm}, N$ is the density of the molecules in $\mathrm{cm}^{-3}$ and $n(\lambda)$ is the wavelength dependent refractive index. This convention is used throughout this work. The Rayleigh formula (Eq. 2) relates the scattering cross section to two directly measurable 
quantities; the refractive index and the gas density. Note that the latter two are macroscopic properties of the gas related such that $\sigma_{R}$ represents a single-particle cross section. A comparison between measurements of the Rayleigh cross section and the refractive index, for a known density, yields information on the dimensionless King correction factor $F_{k}(\lambda)$ [15]. This factor accounts for the anisotropy in scattering by non-spherical molecules, which is important for the description of polarization and angular-dependent effects and is defined by

$$
F_{k}(\lambda)=\frac{3+6 \rho_{p}(\lambda)}{3-4 \rho_{p}(\lambda)}=\frac{6+3 \rho_{n}(\lambda)}{6-7 \rho_{n}(\lambda)}
$$

Here $\rho_{\mathrm{p}}$ and $\rho_{\mathrm{n}}$ stand for the depolarization ratio of either polarized or natural (unpolarized) incident light, respectively, which is specified in Refs. [16, 19, 20, 21]. The role of molecular polarization effects becomes significantly stronger in the deep UV compared to the visible. Consequently, the depolarization ratio of investigated molecular species must be taken into account as well [22].

\section{Experiment}

The experimental setup and approach to measure Rayleigh scattering cross sections have been described in detail previously [6, 23, 24] and are based upon direct absorption spectroscopy applying CRDS. Pulsed laser radiation is obtained by frequency doubling of the blue-green output of a Spectra Physics PDL-2 dye laser (operated on Coumarin 152, Coumarin 307 and Stilbene 3 laser dyes), pumped by a $355 \mathrm{~nm} \mathrm{Nd:YAG} \mathrm{laser} \mathrm{at} 10 \mathrm{~Hz}$ repetition rate, yielding wavelengths at 270.15, 251.72, 215.38 and $210.12 \mathrm{~nm}$. Wavelengths at 203.76, 199.27, 198.48 and $197.70 \mathrm{~nm}$ are generated by frequency-tripling the output of a pulsed (SIRAH) dye laser, running near $600 \mathrm{~nm}$ on Rhodamine-B dye and pumped by a Nd:YAG laser at $532 \mathrm{~nm}$, also at $10 \mathrm{~Hz}$ repetition rate. The final band width, in both configurations, is better than $0.2 \mathrm{~cm}^{-1}$ and the absolute accuracy of the wavelength calibration, performed by an echelle-grating spectrometer, is of the order of $0.01 \mathrm{~nm}$. 
The laser light is focused into an optical cavity comprising of two highly reflective mirrors and the light leaking out is detected by a photo-multiplier tube (Hamamatsu H9858 series) and subsequently digitized by a LeCroy9450 $350 \mathrm{MHz}$ oscilloscope. The reflectivity of the CRD mirrors $\left(r_{\text {curv }}=25 \mathrm{~cm}\right)$ is better than $99.4 \%$ in the $215.38-270.15$ $\mathrm{nm}$ region and $\sim 98 \%$ at $210.12 \mathrm{~nm}$. These mirrors are mounted onto a $40 \mathrm{~cm}$ long cell, resulting in decay times of about $250 \mathrm{~ns}$ (5\% uncertainty). High-quality mirrors $\left(\mathrm{r}_{\text {curv }}=1\right.$ m) have been obtained (from LaserOptik) with an effective reflectivity of $99.2 \%$ in the 198-201 nm region; this constitutes a major improvement over previous deep-UV CRDS experiments [25]. The mirrors are mounted onto an $82 \mathrm{~cm}$ long cell, previously designed for pressure ramp CRDS studies [24]. This cell contains a multitude of inlet holes for the gas to enter the scattering region, while avoiding turbulence effects. The pressure in both cells is measured with high precision (0.15\%) using an Edwards type 600AB Baratron. Pressure ramps are used to separate the molecular extinction signal from cavity losses and to extract absolute absorption cross sections [23]. For this both the pressure and the decay time of the cavity are continuously monitored, while gradually increasing the gas density in the scattering region.

The decay rate $\beta$ obtained in this CRDS measurement, equaling the inverse of the ring down decay time $\tau$, scales with the gas density

$$
\beta=\frac{c|\ln R(\lambda)|}{d}+c \sigma N .
$$

Hence, from a series of measurements at fixed wavelength and at increasing gas density $\mathrm{N}$, both the averaged reflectivity $\mathrm{R}(\lambda)$ of the mirror set and the absolute extinction cross section $\sigma$ can be obtained. Note that the latter follows from the slope of each $\beta$ vs. $\mathrm{N}$ measurement and that the resulting value is independent of the cell length d. CRDS pressure ramp scans have been recorded in pressure ranges up to atmospheric pressure. At every momentary pressure value, five decay transients are digitized and fitted. The slope coefficient of each individual pressure ramp measurement is determined with an accuracy of a few percent. The resulting cross-section values over the entire set of measurements are 
spread over a relatively large range and therefore a significant number of pressure ramp scans (typically 10) has been taken to statistically decrease the experimental error. All measurements have been taken at $293 \pm 3 \mathrm{~K}$.

High purity gases are used $\left(99.999 \%\right.$ for $\mathrm{N}_{2}, 99.995 \%$ for $\mathrm{CH}_{4}$ and $99.8 \%$ for $\mathrm{SF}_{6}$ ) and a 0.5 micron filter cleans the injected gas from dust and aerosol particles, which may affect the scattering properties of the gas. It should be noted that the laser wavelength is not scanned during subsequent gas fillings, as only for fixed wavelengths frequency-dependent baseline fluctuations can be excluded. This also explains why only a limited number of frequency measurements is presented here, well distributed over the region of interest.

\section{Results and discussion}

The resulting extinction curves for $\mathrm{N}_{2}, \mathrm{CH}_{4}$ and $\mathrm{SF}_{6}$ are shown in Figs. 1, 3 and 5, respectively. In Table 1 the measured and predicted extinction cross sections (with $1 \sigma$ uncertainties) are listed using Eq. (2). These predicted values are calculated to equal the Rayleigh scattering cross-section values, and hence it is assumed that no absorption occurs. Formulas for the refractive indices and for the King correction factor are taken from the literature and extrapolated to the deep-UV region, if necessary.

It should be noted that due to the wavelength dependence of the refractive index and the King correction factor, the Rayleigh scattering cross section is not exactly proportional to $1 / \lambda^{4}$. Consequently, a proper mathematical function accounting for this difference, see Ref. [26], has to be used as demonstrated previously [6, 23, 24],

$$
\sigma_{R}=\sigma v^{(4+\varepsilon)}
$$

where $v$ is the light frequency in $\mathrm{cm}^{-1}$. Hence the wavelength-dependent Rayleigh scattering $\sigma_{\mathrm{R}}$ is expressed in terms of two variables $\sigma$ and $\varepsilon$. In this functional representation is $\varepsilon$ a dimensionless parameter and the dimension of $\sigma$ consequently depends on the value of $\varepsilon$. In the following this is not addressed further. A simultaneous fit of both variables results in large error margins because of a strong correlation. Therefore a two step fitting procedure has been applied: the $\sigma$ parameter is kept fixed to the predicted and 
uncorrected theoretical value (calculated from the refractive index and the King correction factor), while the value for $\varepsilon$ is repeatedly optimized. During the second step free and fixed parameters are interchanged and statistically reliable values are found after a few iterations. The experimental and predicted values for the three gases studied here are given in Table 2.

\section{Molecular nitrogen}

Accurate information (with an uncertainty of about $2 \times 10^{-5}$ percent) of the $\mathrm{N}_{2}$ refractive index behavior in the $145-270 \mathrm{~nm}$ region is available for $273.15 \mathrm{~K}$ and $101325 \mathrm{~Pa}$ from Refs. [27, 28]. To convert the refractive index data from Ref. [28] to the present laboratory conditions (293 K, similar pressure) the following equation is used [28, 29];

$$
\frac{n_{1}-1}{n_{2}-1}=\frac{P_{1} T_{2} Z_{2}}{P_{2} T_{1} Z_{1}}\left(1+\frac{n_{1}}{6}\left(1-\frac{P_{2} T_{1}}{P_{1} T_{2}}\right)\right),
$$

with $n_{i}$ the refractive index at pressure $P_{i}[\mathrm{~Pa}]$ and temperature $T_{i}[K]$ and where $Z$, the value of gas compressibility is given by $[28,29]$

$$
Z_{i}=1-\frac{P_{i}}{101325}\left(317.6-T_{i}\right) \times 10^{-5}
$$

In this way 31 measured values of refractive indices $n_{i}\left(\lambda_{i}\right)$ [28] were scaled to $293 \mathrm{~K}$ and $101325 \mathrm{~Pa}$ and then fitted to a two term Sellmeier formula [30], resulting in the dispersion relationship;

$$
n(\lambda)-1=\left(\frac{3.635 \cdot \lambda^{2}}{43.878 \times 10^{-5} \cdot \lambda^{2}-1}+\frac{0.0261 \cdot \lambda^{2}}{0.134 \times 10^{-5} \cdot \lambda^{2}-1}\right) \times 10^{-8}
$$

The absolute uncertainty achieved during the fit is better than $0.1 \%$. This determines the final uncertainty in the dispersion formula, since the error of the measured values of the refractive index is much smaller.

The King correction factor for the $200-632.8 \mathrm{~nm}$ region is available with an uncertainty better than one percent from Ref. [27] and given in Eq. (9); 


$$
F_{k}(\lambda)=1.03+\frac{3.17 \times 10^{-12}}{\lambda^{2}} .
$$

Seven data points for the wavelength dependent Rayleigh cross section of $\mathrm{N}_{2}$ are indicated in Fig. 1a. The points follow a dashed line that represents the prediction of the Rayleigh scattering cross section based on dispersion relationships, given by Eqs. (8) and (9). The solid line in Fig. 1a represents the fit for the resulting $\sigma=1.80 \times 10^{-46}$ and $\varepsilon=$ 0.543 values as listed in Table 2. The difference between the calculated and predicted values and the corresponding uncertainty range by the present fit representation is plotted in the lower graph (Fig. 1b). All values overlap within their uncertainties, with exception of the $270.15 \mathrm{~nm}$ results. This may be due to the relatively low experimental sensitivity at this wavelength.

Since $\mathrm{N}_{2}$ is a non-spherical molecule significant depolarization effects are expected in the deep-UV domain. To estimate how strong these effects are, a further quantitative analysis of the experimental data set has been performed and refractive index and King correction factor values have been derived using the current fit representation, as defined in Eq. (5). The King correction factor values are derived using Eq. (2), assuming that the refractive index dispersion is equal to Eq. (8). A similar approach has been used to calculate the refractive index values for $\mathrm{N}_{2}$, using Eq. (9). The molecular volume polarizability values have been calculated directly from Eq. (1), assuming that the Rayleigh scattering cross sections are equal to those predicted by the fit representation as given by Eq. (5). The values of the depolarization ratio for polarized light have been calculated using Eq. (3). The resulting values for $F_{k}{ }^{\exp }(\lambda), n^{\exp }(\lambda), \alpha_{v o l} \exp ^{\operatorname{ex}}(\lambda)$ and $\rho_{p}{ }^{\exp }(\lambda)$ are plotted in Figs. 2a through d, respectively (see figure caption for detailed information). In all cases the confidence intervals that are based on the experimental uncertainties are plotted as well. This shows that the values calculated from the fit representation using the measured Rayleigh scattering cross sections are in good quantitative agreement (within the specified uncertainty) with data available from literature [7, 27, 28,]. The deviation between the calculated values of the King correction factor, refractive index, molecular 
volume polarizability and the depolarization ratio becomes smaller towards $300 \mathrm{~nm}$. It should be noted that the difference between values of the King correction factor, derived from the present Rayleigh scattering cross-section determinations and the values, available from Ref. [27] is larger than that of the refractive index data. This is also reflected in the discrepancy between calculated and theoretical values of the molecular volume polarizability and the depolarization ratio. The reason for this is a general lack of depolarization measurements in the deep-UV domain (shorter than $300 \mathrm{~nm}$ ).

The outcome confirms that the light extinction in the deep UV for $\mathrm{N}_{2}$ is fully determined by Rayleigh scattering and that there is no evidence for a (detectable) absorption onset in the studied wavelength region.

\section{Methane}

Six data points for the wavelength dependent Rayleigh cross section of $\mathrm{CH}_{4}$ were measured and are plotted in Fig. 3. Methane refractive index data have been reported only in the interval between 325.13 and $632.99 \mathrm{~nm}$, based on the polarizability measurements given in Ref. [31]. Other information, particularly depolarization measurements, is largely lacking. A comparison with the depolarization effects for the symmetrically comparable $\mathrm{CCl}_{4}$ at $632.8 \mathrm{~nm}$ suggests that these are small [16] and it seems reasonable to set $F_{k}(\lambda)=1$ for methane. The dispersion formula for the refractive as extracted in Ref. [24] from the experimental data in Ref. [31] is used to calculate the Rayleigh scattering cross sections.

$$
n(\lambda)-1=\left(46662+\frac{4.02 \times 10^{-6}}{\lambda^{2}}\right) \times 10^{-8} .
$$

In view of the very limited number of refractive index measurements the accuracy of this equation is assumed to be on the level of 4\% [24]. Extrapolation to the deep UV, as necessary here, most likely gives rise to additional uncertainty.

The values that result from the extinction measurements are plotted in Fig. 3a. For a quantitative estimate of the difference between the measured and predicted $\sim 1 / \lambda^{4}$ Rayleigh scattering behavior in $\mathrm{CH}_{4}$ (based on dispersion), a non-linear least square fit along Eq. (5) 
has been made that is included in Fig. 3 as well. The resulting values for $\sigma$ and $\varepsilon$ are listed in Table 2. The discrepancy between the dispersion-related and CRDS derived cross sections is below $10 \%$ (Fig. 3b).

As for molecular nitrogen values for the refractive index and the molecular volume polarizability have been derived for methane. For this depolarization effects are neglected and $F_{k}(\lambda)=1$ is taken for all wavelengths. The resulting curves for the refractive index and molecular volume polarizability are plotted in Figs. 4a and 4b. The estimated discrepancy between the calculated and predicted values of the refractive index values is less than $6 \%$ (Fig. 4c), originating from inaccuracies in the CRDS measurements and from the extrapolation of the dispersion formula for the refractive index in $\mathrm{CH}_{4}$. This is comparable with the absolute uncertainty of the dispersion formula of $\sim 4 \%$ in the $325-632 \mathrm{~nm}$ region $[24,31]$. Also here, the outcome confirms that the deep-UV light extinction is fully governed by Rayleigh scattering and that the refractive index in $\mathrm{CH}_{4}$ in the deep-UV domain can be described by the dispersion relationship in form of Eq. (10) within a few percent uncertainty. The molecular volume polarizability values, calculated from the present CRDS measurements are found to be in a good agreement with the data available from Ref. [32].

It is important to note that the purity of the $\mathrm{CH}_{4}$ gas used is critical. In a first set of measurements with purity less than $99.5 \%$ and most likely hydrocarbon-like impurities an absorption onset was found around $\sim 210 \mathrm{~nm}$ that definitely cannot be attributed to methane.

\section{Sulphur hexafluoride}

In Fig. 5 the data point set for the wavelength dependent Rayleigh cross section of $\mathrm{SF}_{6}$ is shown. In the literature a limited data set of $\mathrm{SF}_{6}$ refractive indices and extinction coefficient measurements have been reported $[12,13,24]$. Sulphur hexafluoride is a highly symmetrical molecule, so $F_{k}(\lambda)=1$ is used. The derived empirical formula for dispersion 
of the refractive index, based on measurements at 633 and $1300 \mathrm{~nm}$ [33] has been used in the UV-VIS [23, 24, 25]:

$$
n(\lambda)-1=\left(71517+\frac{5 \times 10^{-6}}{\lambda^{2}}\right) \times 10^{-8} .
$$

The data points follow a dashed line that represents predictions of Rayleigh scattering cross-section values based on available dispersion data, as can be seen in Fig. 5. This line coincides with a solid line that is the fit representation for $\sigma=17.90 \times 10^{-46}$ and $\varepsilon=$ 0.490(4) as summarized in Table 2. The measured and predicted Rayleigh scattering cross sections agree within $2 \%$ for the deep-UV domain, and the overall picture indicates that light extinction in $\mathrm{SF}_{6}$ gas is governed by Rayleigh scattering in the entire studied wavelength interval.

Additional information is available from Fig. 6 that shows the refractive index (solid black line in Fig. 6a) and the molecular volume polarizability (solid line in Fig. 6b) values, derived from the fit representation of the measured Rayleigh scattering cross-section values. The dashed lines in Fig. 6 show the predicted values derived from the Rayleigh scattering cross section, based on dispersion data available from literature [24].

The comparison made for calculated molecular volume polarizability values shows that $\mathrm{SF}_{6}$ has the largest polarizability among all investigated gas species. The error margins that originate from the absolute uncertainty of the $\sigma$ and $\varepsilon$ values are shown as grey solid lines in Fig. 6 as well. The literature values [24, 33] are indicated for comparison. From the numerical analysis it can be concluded that despite the lack of laboratory data, the refractive index of $\mathrm{SF}_{6}$ follows the dispersion formula, given by Eq. (11), within a few percent uncertainty, even when extrapolated to the deep UV.

\section{Conclusions}

Extinction coefficients have been measured for gaseous $\mathrm{N}_{2}, \mathrm{CH}_{4}$ and $\mathrm{SF}_{6}$ at room temperature between 197.7 and $270.15 \mathrm{~nm}$ applying cavity ring down spectroscopy to 
pressure ramp measurements. A non-linear squares fit of a $\sim 1 / \lambda^{4}$ like function shows the actual behavior of the Rayleigh scattering and gives an estimate of the discrepancy between measured and predicted values, based on dispersion formulas as available from literature. The light extinction in the deep UV is for all three molecular systems dominated by Rayleigh scattering. Due to the present lack of experimental data for light extinction cross sections and refractive indices between the deep UV and visible domain, it is not yet possible to construct a universal empirical relation that accurately predicts the $1 / \lambda^{4}$ Rayleigh scattering behavior for the entire UV-VIS region.

\section{Acknowledgments}

The authors thank J. Bouma for technical support and the Netherlands Foundation for Fundamental Research (FOM) for financial support via their Molecular Atmospheric Physics (MAP) program. 


\section{$\underline{\text { References }}$}

1. H. Horvath, Atmospheric Environment, 27A, 293 (1993).

2. R.R. Meier, G. P. Anderson, C. A. Cantrell, L. A. Hall, J. Lean, K. Minschwaner, R.

E. Shetter, E. P. Shettle and K. Stamnes, J. Atmos. Solar-Terrestr. Phys., 59, 2111 (1997).

3. A. C. Eckbreth: Laser Diagnostics for Combustion Temperature and Species (Abacus, Cambridge, MA 1988).

4. D. E. Shemansky, J. Chem. Phys. 56, 1582 (1972).

5. A. Karaiskou, C. Vallance, V. Papadakis, I. M. Vardavas, T. P. Rakitzis, Chem. Phys. Lett. 400, 30 (2004).

6. D. Ityaksov, H. Linnartz, W. Ubachs, Chem. Phys. Lett. 462, 31 (2008).

7. W. Reckers, Y. Gu, E. W. Rothe and H. Voges, Appl. Spectr. 51, 1012 (1997).

8. L. C. Lee, C.C. Chiang, J. Chem. Phys. 78, 688 (1983).

9. F. Z. Chen, C. Y. R. Wu, J. Quant. Spectrosc. Radiat. Transfer, 85, 195 (2004).

10. R. van Harrevelt, J. Chem. Phys. 126, 204313 (2007).

11. M. Maiss, A. M. Brenninkmeijer, Environ. Sci. Technol. 32, 3077 (1998).

12. E. D. Nostrand, A. B. F. Duncan, J. Am. Chem. Soc. 76, 3377 (1954).

13. C. Pradayrol, A. M. Casanovas, I. Deharo, J. P. Guelfucci, J. Casanovas, J. Phys. III France 6, 603 (1996).

14. J. W. Strutt, Philos. Mag. 47, 375 (1899).

15. L. V. King, Proc. Roy. Soc. (London) 104, 333 (1923).

16. N. J. Bridge, A. D. Buckingham, Proc. Roy. Soc. (London) A295, 334 (1966).

17. A. Bucholtz, Appl. Opt. 34, 2765 (1995).

18. C. M. Penney, J. Opt. Soc. Am. 59, 34 (1969).

19. J. Oddershede, E. N. Svendsen, Chem. Phys. 64, 359 (1982).

20. E. Dayan, J. Chem. Soc. Faraday Trans. II, 76, 309 (1980).

21. J. A. Sutton, J. F. Driscoll, Opt. Lett. 29, 2620 (2004). 
22. M. P. Bogaard, A. D. Buckingham, R. K. Pierens and A. H. White, J. Chem. Soc. Faraday Trans., 74, 3008 (1978).

23. H. Naus, W. Ubachs, Opt. Lett. 25, 347 (2000).

24. M. Sneep, W.Ubachs, J. Quant. Spectrosc. Radiat. Transfer, 92, 293 (2005).

25. M. Sneep, S. Hannemann, E. J. van Duijn, W. Ubachs, Opt. Lett. 29, 1378 (2004).

26. P. M. Teillet, Appl. Opt. 29, 1897 (1990).

27. D. R. Bates, Planet. Space Sci. 32, 785 (1984).

28. U. Griesmann, J. H. Burnett, Opt. Lett. 24, 1699 (1999).

29. E. R. Peck, B.N. Khanna, J. Opt. Soc. Am. 56, 1059 (1966).

30. B. Tatian, Appl. Opt., 23, 4477 (1984).

31. U. Hohm, Mol. Phys. 78, 929 (1993).

32. A. Koch, H. Voges, P. Andersen, H. Schuter, D. Wolff, W. Hentschel, W. Oppermann, E. Rothe, Appl. Phys. B 56, 177 (1993).

33. D. Vukovic, G. A. Woolsey, G. B. Scelsi, J. Phys. D 29, 634 (1996).

34. Landolt-Bornstein: Zahlenwerte und Funktionen, $6^{\text {th }}$ ed. (Springer Berlin, Heidelberg, 1962) Vol. II, part 8, Optische Konstanten. 


\section{Table 1}

Measured and predicted light extinction cross-section values in the $197.7-270.15 \mathrm{~nm}$ region for $\mathrm{N}_{2}, \mathrm{CH}_{4}$ and $\mathrm{SF}_{6}$, obtained from $\mathrm{CRD}$ pressure ramp measurements.

\begin{tabular}{|c|c|c|c|c|c|c|}
\hline \multirow{2}{*}{$\lambda[\mathrm{nm}]$} & \multicolumn{6}{|c|}{ Extinction cross section/ $10^{-25}\left[\mathrm{~cm}^{2}\right]$} \\
\cline { 2 - 7 } & \multicolumn{2}{|c|}{$\mathrm{N}_{2}$} & \multicolumn{2}{|c|}{$\mathrm{CH}_{4}$} & \multicolumn{2}{|c|}{$\mathrm{SF}_{6}$} \\
\cline { 2 - 7 } & measured & predicted $^{a, b, e}$ & measured & predicted $^{c, e}$ & measured & predicted $^{d, e}$ \\
\hline 197.70 & $3.39 \pm 0.30$ & $3.62 \pm 0.09$ & $11.92 \pm 0.64$ & $10.82 \pm 0.03$ & $26.86 \pm 2.54$ & 23.71 \\
\hline 198.48 & $3.60 \pm 0.18$ & $3.55 \pm 0.08$ & $12.59 \pm 1.30$ & $10.62 \pm 0.03$ & $19.35 \pm 2.22$ & 23.28 \\
\hline 199.27 & $4.22 \pm 0.80$ & $3.48 \pm 0.08$ & $11.09 \pm 2.42$ & $10.43 \pm 0.03$ & $20.68 \pm 2.14$ & 22.86 \\
\hline 203.76 & $3.38 \pm 0.59$ & $3.14 \pm 0.08$ & & $9.39 \pm 0.02$ & & 20.64 \\
\hline 210.12 & & $2.7 \pm 0.1$ & & $8.13 \pm 0.02$ & $18.33 \pm 4.04$ & 17.94 \\
\hline 215.38 & $2.61 \pm 0.42$ & $2.43 \pm 0.06$ & $7.79 \pm 1.25$ & $7.25 \pm 0.02$ & $16.09 \pm 2.59$ & 16.04 \\
\hline 251.72 & $1.33 \pm 0.10$ & $1.21 \pm 0.03$ & $3.56 \pm 0.2$ & $3.57 \pm 0.01$ & $8.06 \pm 1.35$ & 8.00 \\
\hline 270.15 & $1.17 \pm 0.17$ & $0.89 \pm 0.02$ & $2.53 \pm 0.33$ & $2.61 \pm 0.01$ & $5.98 \pm 0.40$ & 5.88 \\
\hline
\end{tabular}

${ }^{a)}$ Dispersion relationship, derived from refractive index measurements in Ref. [28].

${ }^{b)}$ Dispersion formula for King correction factor, available from Ref. [27].

c), d) Dispersion relationships for the refractive indices, available from Ref. [24].

e) The absolute error values given here are derived from the uncertainties of the King correction factor and the refraction index dispersion relationships. For $\mathrm{SF}_{6}$ the latter is not available, which is the reason why in the last column no error values can be listed. 
Table 2.

Results of a non-linear square fit of Eq. (5) to the experimental data points, both from the present work and from literature, for $\mathrm{N}_{2}, \mathrm{CH}_{4}$ and $\mathrm{SF}_{6}$ gas.

\begin{tabular}{|c|c|c|c|c|c|}
\hline \multirow{3}{*}{$\mathrm{Gas}$} & \multicolumn{3}{|c|}{ Fit representation } & \multirow{2}{*}{$\begin{array}{c}\text { Wavelength interval } \\
{[\mathrm{nm}]}\end{array}$} \\
\cline { 2 - 5 } & \multicolumn{2}{|c|}{$\sigma\left[10^{-46}\right]$} & \multicolumn{2}{|c}{$\varepsilon$} & \\
\cline { 2 - 5 } & experimental $^{\text {predicted }}{ }^{a}$ & experimental & predicted $^{a}$ & \\
\hline $\mathrm{N}_{2}$ & $1.80 \pm 0.06$ & 1.796 & $0.534 \pm 0.003$ & 0.529 & $197.70-270.15$ \\
\hline $\mathrm{CH}_{4}$ & $0.94 \pm 0.02$ & 0.942 & $0.699 \pm 0.002$ & 0.689 & $197.70-270.15$ \\
\hline $\mathrm{SF}_{6}$ & $17.90 \pm 0.76$ & 17.897 & $0.490 \pm 0.004$ & 0.490 & $197.70-270.15$ \\
\hline
\end{tabular}

${ }^{a}$ Values for $\sigma$ and $\varepsilon$, derived from the fit, performed to predicted (dispersion-based) values of Rayleigh scattering cross section. 


\section{Figure Captions}

\section{Figure 1.}

a: The Rayleigh scattering cross-section behavior of $\mathrm{N}_{2}$ derived from a combined CRD - pressure ramp experiment (black circles). The dashed line represents the Rayleigh scattering cross-section values, calculated from dispersion data for refractive indices taken from Ref. [28] and for a King correction factor as used in Ref. [27]. The solid line shows the fit representation for $\sigma=1.80(6) \times 10^{-46}$ and $\varepsilon=0.534$ (3).

b: The difference between calculated (from the dispersion) and fitted (from CRDS measurements) values, plotted as a solid line. The dashed lines indicate the confidence interval, based on the uncertainties of $\sigma$ and $\varepsilon$ (Table 2).

Figure 2. Different comparisons between the present experimental results and previous dispersion data:

a: The calculated behavior of the $\mathrm{N}_{2}$ King correction factor: the black dashed line follows Eq. (9) [27] and the thin dashed lines indicate the corresponding error margins. The solid black line is calculated from the present Rayleigh scattering cross-section measurements and the refractive index values, given by Eq. (8). Error margins are again plotted as thin solid lines.

b: The calculated behavior of the $\mathrm{N}_{2}$ refractive index: the black dashed line corresponds to the dispersion relationship, given by Eq. (8), open circles indicate the refractive index measurements from Ref. [28] at 273.15 K. The black solid line corresponds to refractive index values as calculated from the present Rayleigh scattering cross-section measurements and the King correction factor, given by Eq. (9). The error margins are indicated by thin solid lines.

c: The $\mathrm{N}_{2}$ molecular volume polarizability values (black solid line), calculated from the fit representation of the present Rayleigh scattering cross-section measurements. The error margins are indicated by thin solid lines. The dashed line represents values, calculated from the dispersion formulas, Eqs. (8) and (9), for the refractive index and King correction factor. The reported results on $\alpha(\lambda)$ in Ref. [7] are indicated by solid squares.

d: The calculated values of the $\mathrm{N}_{2}$ depolarization ratio, derived from Eq. (8) for the King correction factor [27] are shown by a black dashed line. The black solid line corresponds to the calculated values, derived from the present Rayleigh scattering cross-section measurements. Error margins are shown as thin solid lines. Solid triangles correspond to direct depolarization measurements as reported in Ref. [21]. 


\section{Figure 3.}

a: The Rayleigh scattering cross-section behavior of $\mathrm{CH}_{4}$ derived from a combined CRDS - pressure ramp measurement (black circles) and the fit representation (solid line) for $\sigma=0.94(2) \times 10^{-46}$ and $\varepsilon=0.699$ (2). The dashed line represents the Rayleigh scattering cross-section values, calculated from dispersion relationships [24].

b: The difference between calculated and fitted values is shown as a black solid line. Solid thin lines indicate the error margins.

\section{Figure 4.}

a: The $\mathrm{CH}_{4}$ refractive index values, calculated from the Rayleigh scattering cross-section measurements (black solid line). The error margins are indicated by thin solid lines. The black dashed line corresponds to the dispersion formula for the refractive index, given by Eq. (10).

b: The values of the $\mathrm{CH}_{4}$ molecular volume polarizability, calculated from the present study (black solid line). The error margins are plotted as solid grey lines. The dashed line represents the calculated values, calculated from the dispersion formula for the refractive index [24]. Black squares correspond to data, calculated in Ref. [32] from results obtained in Ref. [34].

c: The discrepancy between the refractive index values, derived from the present Rayleigh scattering cross-section measurements and predicted refractive index values, using the dispersion formula as given by Eq. (10).

\section{Figure 5.}

a: The $\mathrm{SF}_{6}$ Rayleigh scattering cross-section behavior derived from a combined CRDS - pressure ramp approach (black circles) and data available from Ref. [25] (empty star). The dashed line represents the calculated Rayleigh scattering cross-section values and the solid line corresponds to the fit representation for $\sigma=17.90(76) \times 10^{-46}$ and $\varepsilon=0.490(4)$.

b: The difference between calculated and fitted values is shown as a solid black line. Solid thin lines indicate the error margins. 


\section{Figure 6.}

a: The $\mathrm{SF}_{6}$ refractive index values, calculated from the Rayleigh scattering cross-section measurements (black solid line). The error margins are given by grey solid lines. The black dashed line corresponds to the dispersion formula for the refractive index taken from Ref. [33] and given by Eq. (11) [24].

b: The molecular volume polarizability behavior, calculated from the present CRDS measurements (black solid line). The error margins are plotted as solid grey lines. The dashed line represents the calculated values, calculated from the dispersion formula for the refractive index [24].

c: The discrepancy between the refractive index values, derived from the present Rayleigh scattering cross-section measurements and the predicted values using the dispersion formula, as given by Eq. (11). 


\section{$\underline{\text { References }}$}

1. H. Horvath, Atmospheric Environment, 27A, 293 (1993).

2. R.R. Meier, G. P. Anderson, C. A. Cantrell, L. A. Hall, J. Lean, K. Minschwaner, R. E. Shetter, E. P. Shettle and K. Stamnes, J. Atmos. Solar-Terrestr. Phys., 59, 2111 (1997).

3. A. C. Eckbreth: Laser Diagnostics for Combustion Temperature and Species (Abacus, Cambridge, MA 1988).

4. D. E. Shemansky, J. Chem. Phys. 56, 1582 (1972).

5. A. Karaiskou, C. Vallance, V. Papadakis, I. M. Vardavas, T. P. Rakitzis, Chem. Phys. Lett. 400, 30 (2004).

6. D. Ityaksov, H. Linnartz, W. Ubachs, Chem. Phys. Lett. 462, 31 (2008).

7. W. Reckers, Y. Gu, E. W. Rothe and H. Voges, Appl. Spectr. 51, 1012 (1997).

8. L. C. Lee, C.C. Chiang, J. Chem. Phys. 78, 688 (1983).

9. F. Z. Chen, C. Y. R. Wu, J. Quant. Spectrosc. Radiat. Transfer, 85, 195 (2004).

10. R. van Harrevelt, J. Chem. Phys. 126, 204313 (2007).

11. M. Maiss, A. M. Brenninkmeijer, Environ. Sci. Technol. 32, 3077 (1998).

12. E. D. Nostrand, A. B. F. Duncan, J. Am. Chem. Soc. 76, 3377 (1954).

13. C. Pradayrol, A. M. Casanovas, I. Deharo, J. P. Guelfucci, J. Casanovas, J. Phys. III France 6, 603 (1996).

14. J. W. Strutt, Philos. Mag. 47, 375 (1899).

15. L. V. King, Proc. Roy. Soc. (London) 104, 333 (1923).

16. N. J. Bridge, A. D. Buckingham, Proc. Roy. Soc. (London) A295, 334 (1966). 
17. A. Bucholtz, Appl. Opt. 34, 2765 (1995).

18. C. M. Penney, J. Opt. Soc. Am. 59, 34 (1969).

19. J. Oddershede, E. N. Svendsen, Chem. Phys. 64, 359 (1982).

20. E. Dayan, J. Chem. Soc. Faraday Trans. II, 76, 309 (1980).

21. J. A. Sutton, J. F. Driscoll, Opt. Lett. 29, 2620 (2004).

22. M. P. Bogaard, A. D. Buckingham, R. K. Pierens and A. H. White, J. Chem. Soc. Faraday Trans., 74, 3008 (1978).

23. H. Naus, W. Ubachs, Opt. Lett. 25, 347 (2000).

24. M. Sneep, W.Ubachs, J. Quant. Spectrosc. Radiat. Transfer, 92, 293 (2005).

25. M. Sneep, S. Hannemann, E. J. van Duijn, W. Ubachs, Opt. Lett. 29, 1378 (2004).

26. P. M. Teillet, Appl. Opt. 29, 1897 (1990).

27. D. R. Bates, Planet. Space Sci. 32, 785 (1984).

28. U. Griesmann, J. H. Burnett, Opt. Lett. 24, 1699 (1999).

29. E. R. Peck, B.N. Khanna, J. Opt. Soc. Am. 56, 1059 (1966).

30. B. Tatian, Appl. Opt., 23, 4477 (1984).

31. U. Hohm, Mol. Phys. 78, 929 (1993).

32. A. Koch, H. Voges, P. Andersen, H. Schuter, D. Wolff, W. Hentschel, W. Oppermann, E. Rothe, Appl. Phys. B 56, 177 (1993).

33. D. Vukovic, G. A. Woolsey, G. B. Scelsi, J. Phys. D 29, 634 (1996).

34. Landolt-Bornstein: Zahlenwerte und Funktionen, $6^{\text {th }}$ ed. (Springer Berlin, Heidelberg, 1962) Vol. II, part 8, Optische Konstanten. 

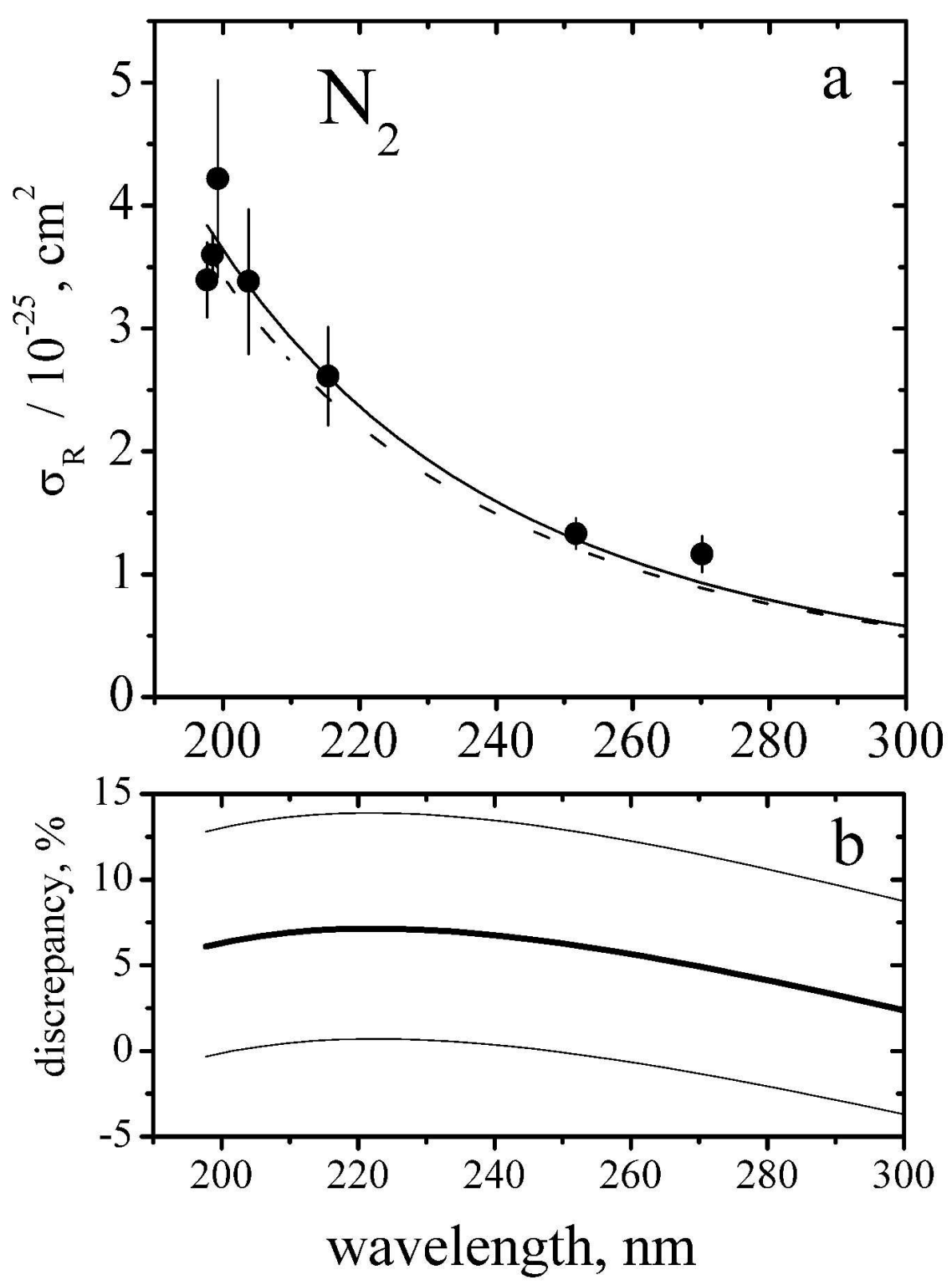

$119 \times 159 \mathrm{~mm}(600 \times 600 \mathrm{DPI})$

URL: http://mc.manuscriptcentral.com/tandf/tmph 

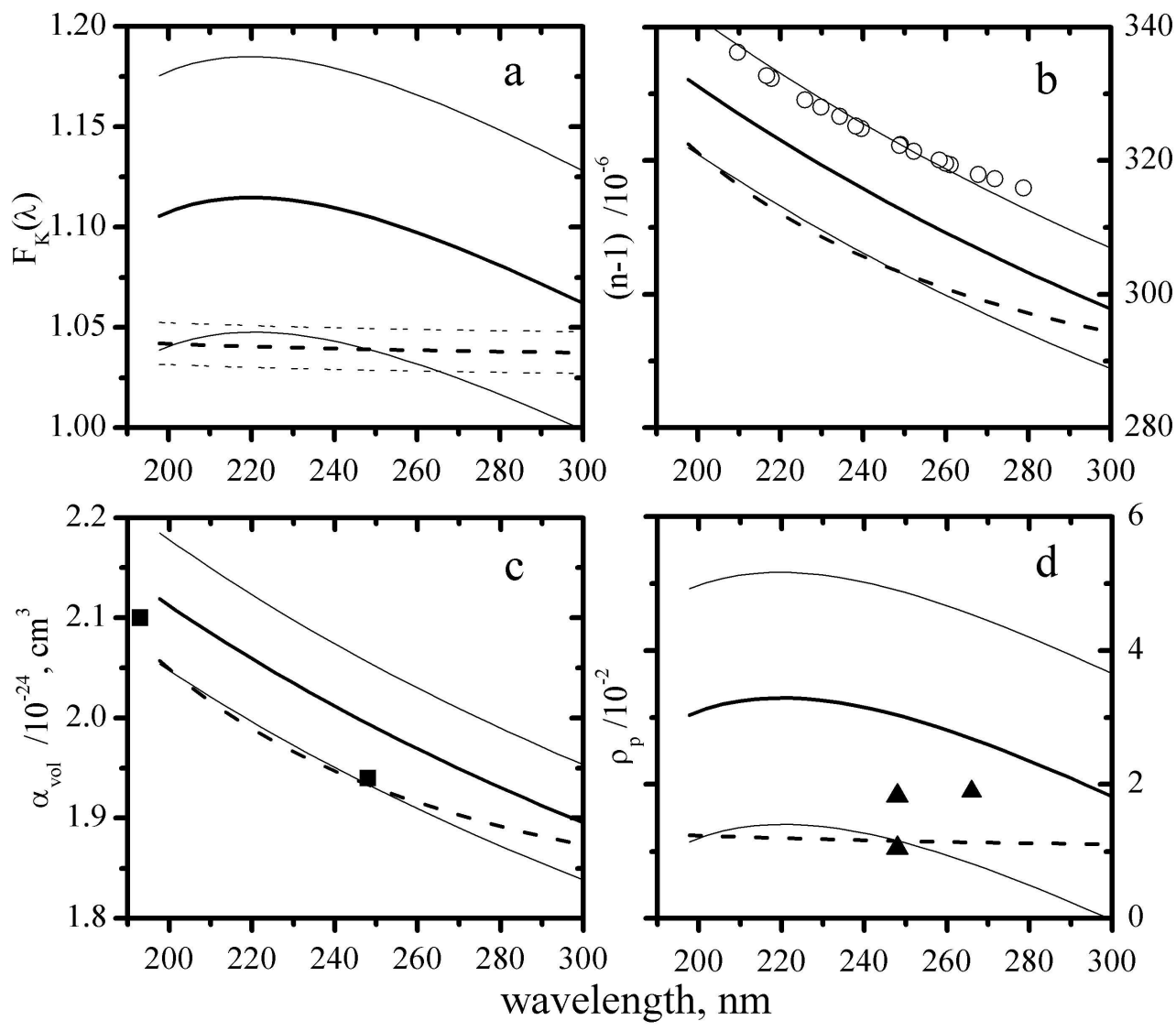

$119 \times 106 \mathrm{~mm}(600 \times 600 \mathrm{DPI})$

URL: http://mc.manuscriptcentral.com/tandf/tmph 

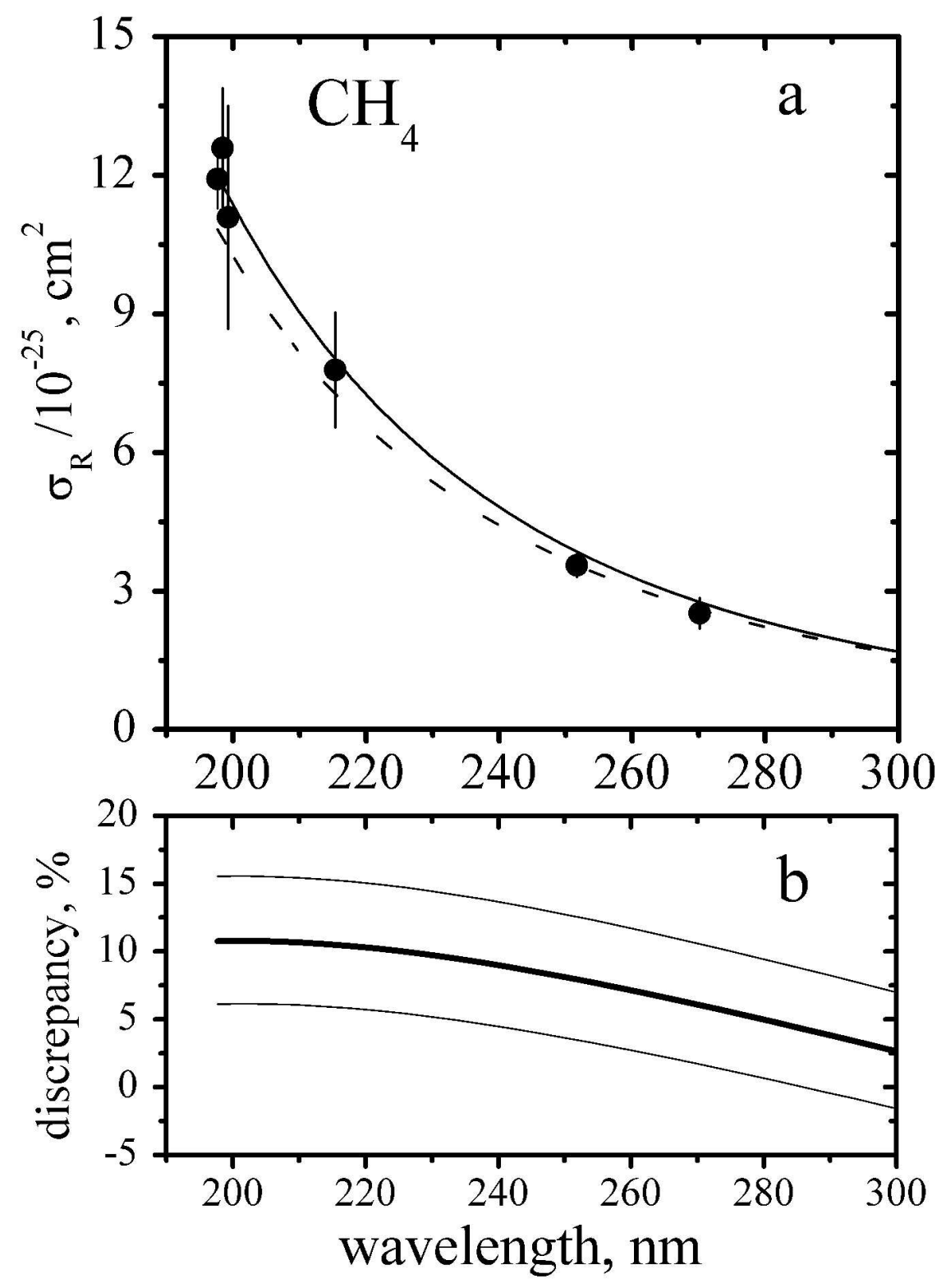

$119 \times 159 \mathrm{~mm}(600 \times 600 \mathrm{DPI})$ 

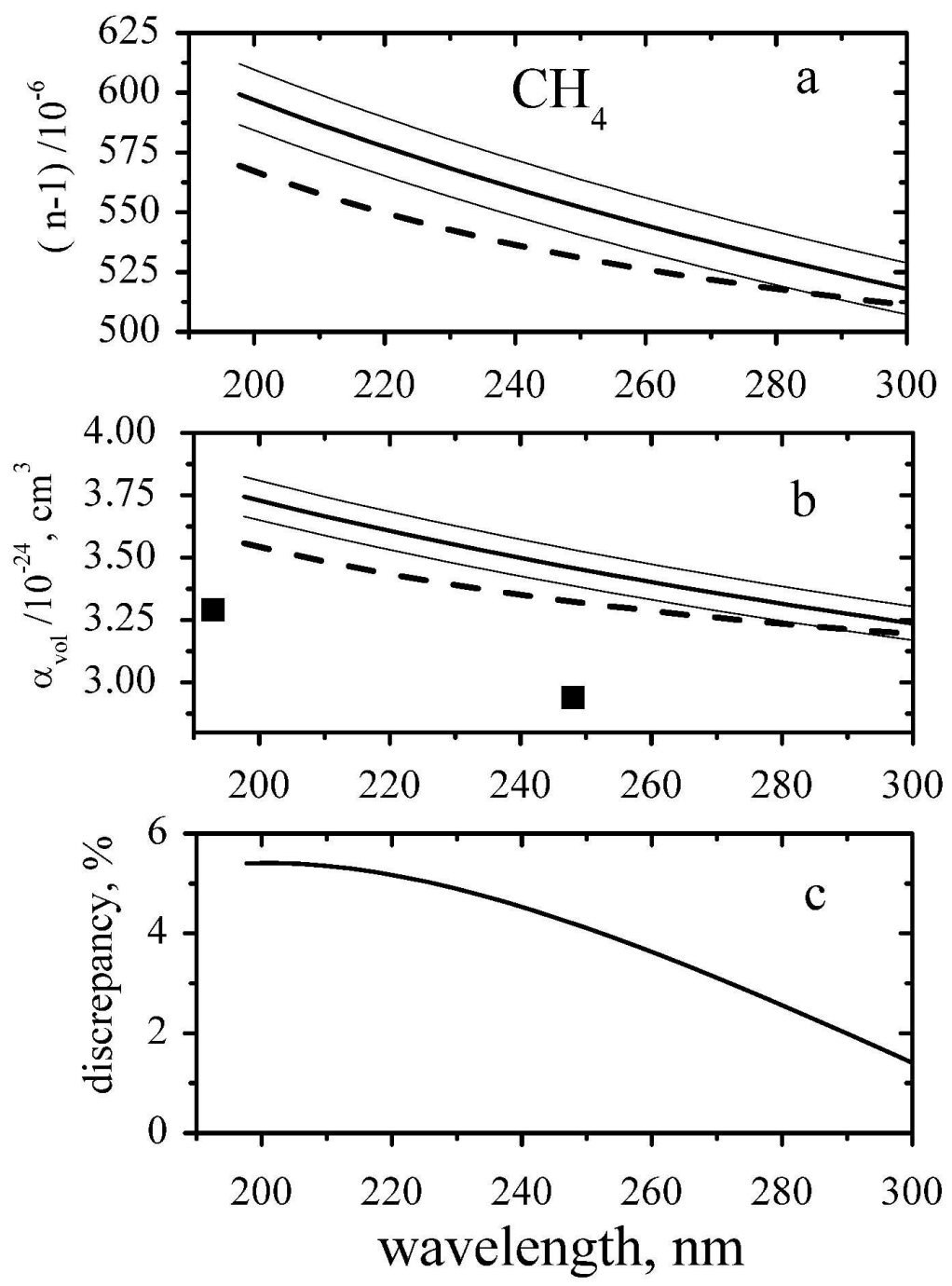

$119 \times 179 \mathrm{~mm}(600 \times 600 \mathrm{DPI})$

URL: http://mc.manuscriptcentral.com/tandf/tmph 

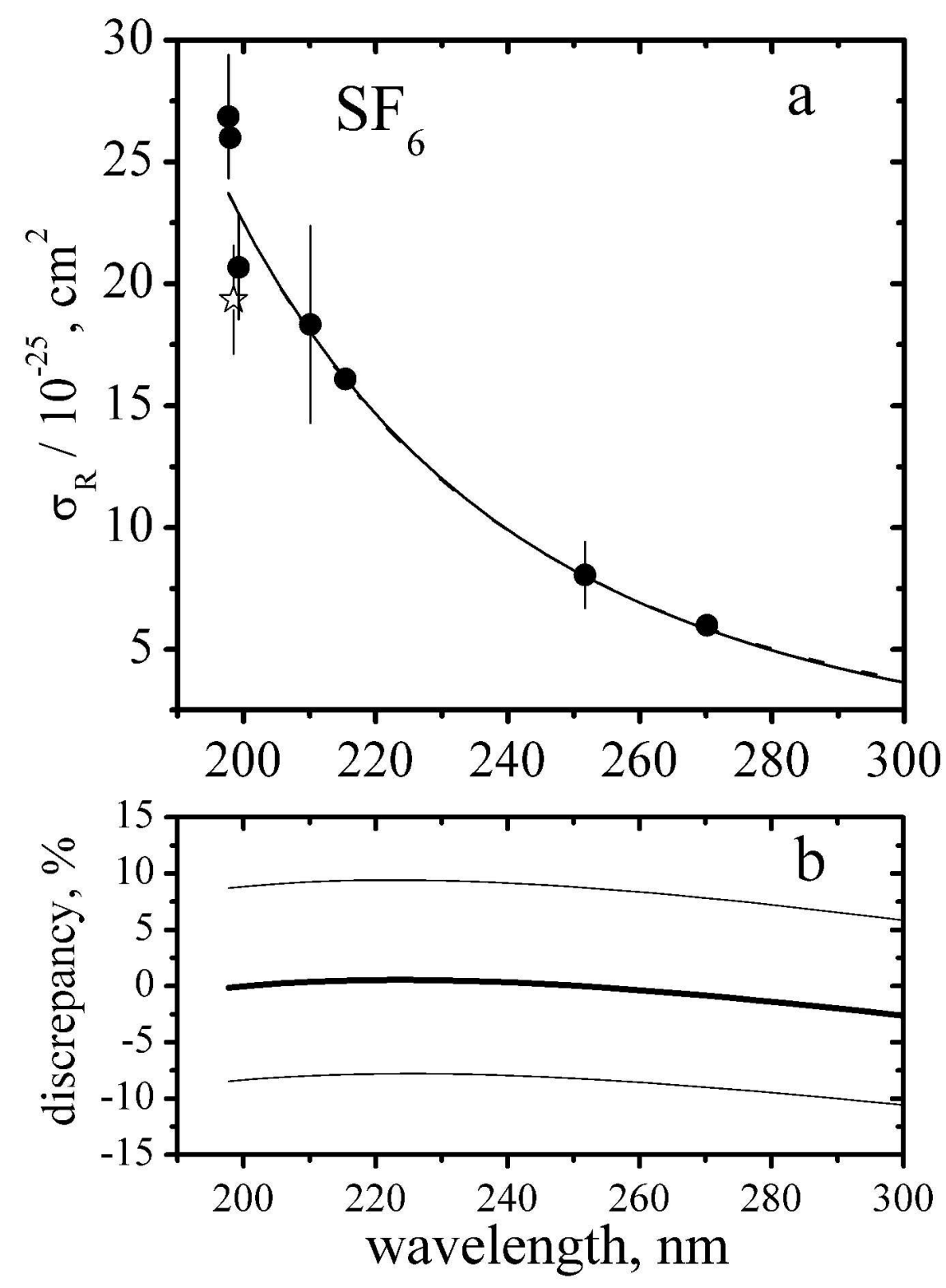

$119 \times 159 \mathrm{~mm}(600 \times 600 \mathrm{DPI})$

URL: http://mc.manuscriptcentral.com/tandf/tmph 

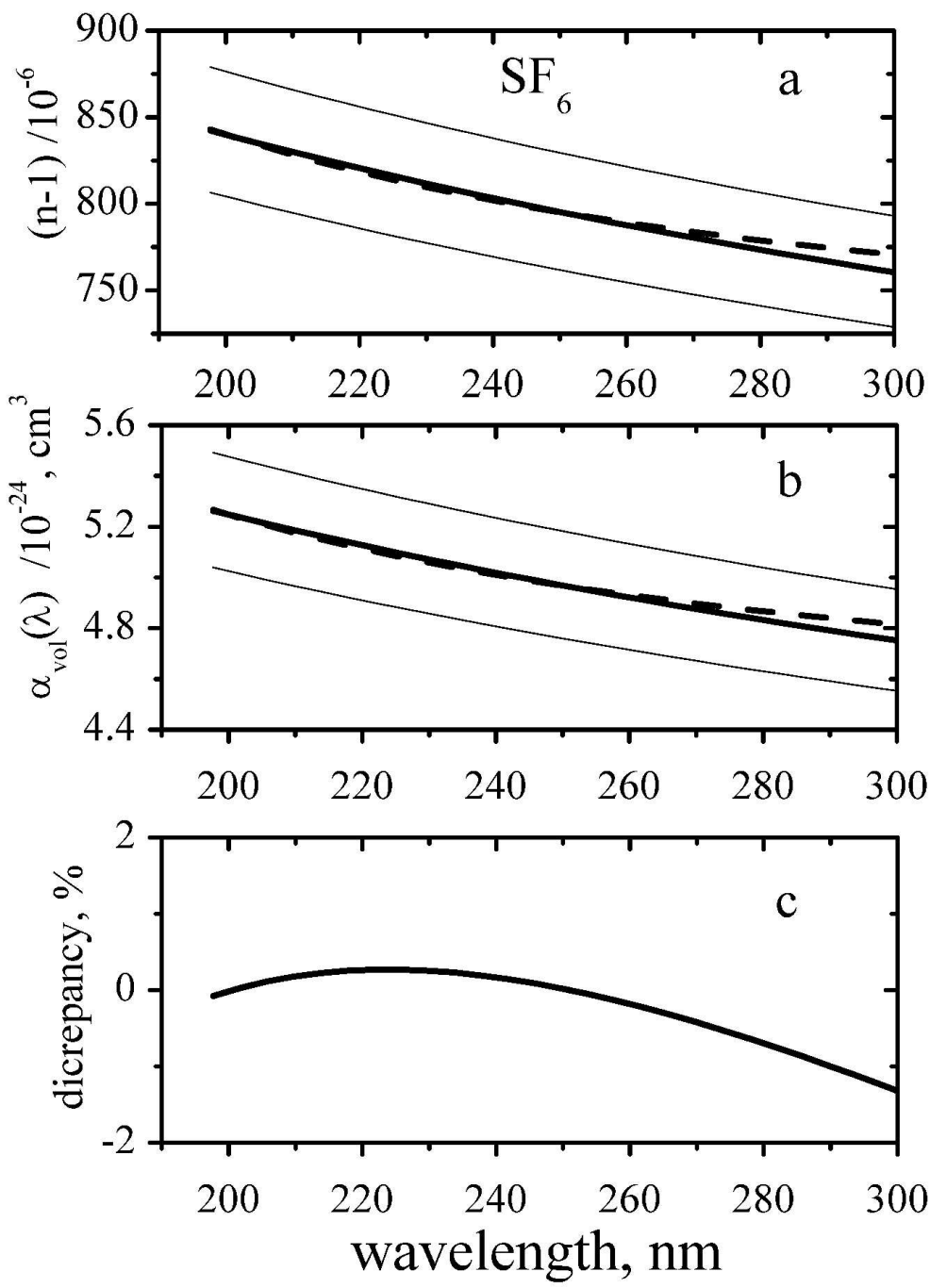

$119 \times 179 m m(600 \times 600$ DPI $)$

URL: http://mc.manuscriptcentral.com/tandf/tmph 


\section{Table 1}

Measured and predicted light extinction cross-section values in the 197.7 $270.15 \mathrm{~nm}$ region for $\mathrm{N}_{2}, \mathrm{CH}_{4}$ and $\mathrm{SF}_{6}$, obtained from CRD pressure ramp measurements.

\begin{tabular}{|c|r|r|r|r|r|r|}
\hline \multirow{2}{*}{$\lambda[\mathrm{nm}]$} & \multicolumn{6}{|c|}{ Extinction cross section/ $10^{-25}\left[\mathrm{~cm}^{2}\right]$} \\
\cline { 2 - 7 } & \multicolumn{2}{|c|}{$\mathrm{N}_{2}$} & \multicolumn{2}{|c|}{$\mathrm{CH}_{4}$} & \multicolumn{2}{|c|}{$\mathrm{SF}_{6}$} \\
\cline { 2 - 7 } & measured & predicted $^{a, b}$, & measured & predicted $^{c, e}$ & measured & predicted \\
\hline 197.70 & $3.39 \pm 0.30$ & $3.62 \pm 0.09$ & $11.92 \pm 0.64$ & $10.82 \pm 0.0 \pm$ & $26.86 \pm 2.5$ & 23.71 \\
\hline 198.48 & $3.60 \pm 0.18$ & $3.55 \pm 0.08$ & $12.59 \pm 1.30$ & $10.62 \pm 0.0 \pm$ & $19.35 \pm 2.22$ & 23.28 \\
\hline 199.27 & $4.22 \pm 0.80$ & $3.48 \pm 0.08$ & $11.09 \pm 2.42$ & $10.43 \pm 0.0 \pm$ & $20.68 \pm 2.1$ & 22.86 \\
\hline 203.76 & $3.38 \pm 0.59$ & $3.14 \pm 0.08$ & & $9.39 \pm 0.02$ & & 20.64 \\
\hline 210.12 & & $2.7 \pm 0.1$ & & $8.13 \pm 0.02$ & $18.33 \pm 4.02$ & 17.94 \\
\hline 215.38 & $2.61 \pm 0.42$ & $2.43 \pm 0.06$ & $7.79 \pm 1.25$ & $7.25 \pm 0.02$ & $16.09 \pm 2.55$ & 16.04 \\
\hline 251.72 & $1.33 \pm 0.10$ & $1.21 \pm 0.03$ & $3.56 \pm 0.2$ & $3.57 \pm 0.01$ & $8.06 \pm 1.35$ & 8.00 \\
\hline 270.15 & $1.17 \pm 0.17$ & $0.89 \pm 0.02$ & $2.53 \pm 0.33$ & $2.61 \pm 0.01$ & $5.98 \pm 0.40$ & 5.88 \\
\hline
\end{tabular}

${ }^{a)}$ Dispersion relationship, derived from refractive index measurements in Ref. [28].

b) Dispersion formula for King correction factor, available from Ref. [27].

c), d) Dispersion relationships for the refractive indices, available from Ref. [24].

e) The absolute error values given here are derived from the uncertainties of the King correction factor and the refraction index dispersion relationships. For $\mathrm{SF}_{6}$ the latter is not available, which is the reason why in the last column no error values can be listed. 


\section{Table 2.}

Results of a non-linear square fit of Eq. (5) to the experimental data points, both from the present work and from literature, for $\mathrm{N}_{2}, \mathrm{CH}_{4}$ and $\mathrm{SF}_{6}$ gas.

\begin{tabular}{|c|c|c|c|c|c|}
\hline \multirow{2}{*}{ Gas } & \multicolumn{4}{|c|}{ Fit representation } & \multirow{2}{*}{$\begin{array}{c}\text { Wavelength interval } \\
{[\mathrm{nm}]}\end{array}$} \\
\cline { 2 - 5 } & \multicolumn{2}{|c|}{$\sigma\left[10^{-46}\right]$} & \multicolumn{2}{|c}{$\varepsilon$} & \\
\cline { 2 - 5 } & experimental $^{\text {predicted }}{ }^{a}$ & experimental & predicted $^{a}$ & \\
\hline $\mathrm{N}_{2}$ & $1.80 \pm 0.06$ & 1.796 & $0.534 \pm 0.003$ & 0.529 & $197.70-270.15$ \\
\hline $\mathrm{CH}_{4}$ & $0.94 \pm 0.02$ & 0.942 & $0.699 \pm 0.002$ & 0.689 & $197.70-270.15$ \\
\hline $\mathrm{SF}_{6}$ & $17.90 \pm 0.76$ & 17.897 & $0.490 \pm 0.004$ & 0.490 & $197.70-270.15$ \\
\hline
\end{tabular}

${ }^{a}$ Values for $\sigma$ and $\varepsilon$, derived from the fit, performed to predicted (dispersion-based) values of Rayleigh scattering cross section. 